\title{
An Analytical Model for Fracture Initiation from a Particular Radial Borehole in Hydraulic Fracturing Guided by Multiradial Boreholes
}

\author{
Yuxin Chen $\mathbb{D}$, Yunhong Ding, Chong Liang, Dawei Zhu, Yu Bai $\mathbb{D}^{\mathbb{D}}$, and Chunmei Zou \\ PetroChina Research Institute of Petroleum Exploration \& Development, Beijing 100083, China \\ Correspondence should be addressed to Yuxin Chen; chen_yuxin@163.com
}

Received 24 November 2020; Revised 7 January 2021; Accepted 25 January 2021; Published 11 February 2021

Academic Editor: Yingfang Zhou

Copyright (c) 2021 Yuxin Chen et al. This is an open access article distributed under the Creative Commons Attribution License, which permits unrestricted use, distribution, and reproduction in any medium, provided the original work is properly cited.

\begin{abstract}
Radial drilling-fracturing, the combination of the hydraulic fracturing and radial borehole, is a technology that can guide the hydraulic fractures to directionally propagate and efficiently develop low permeability reservoir. In this paper, an analytical model of two radial boreholes (a basic research unit) is established to predict fracture initiation pressure (FIP) from one particular radial borehole and the interference between radial boreholes when the hydraulic fracturing is guided by multi-radial boreholes. The model is based on the stress superposition principle and the maximum tensile stress criterion. The effects of in situ stress, wellbore pressure, and fracturing fluid percolation are considered. Then, sensitivity analysis is performed by examining the impact of the intersection angle between radial boreholes, the depth difference between radial boreholes, the radius of radial boreholes, Biot coefficient, and the number of radial boreholes. The results show that FIP declines with the increase of radial boreholes number and the decrease of intersection angle and depth difference between radial boreholes. Meanwhile, the increase of radial borehole number and the reduction of intersection angle and depth difference strengthen the interference between radial boreholes, which conduce to the formation of the fracture network connecting radial boreholes. Besides, FIP declines with the increase of radial borehole radius and the decrease of Biot coefficient. Large radius and low Biot coefficient can enlarge the influence range of additional stress field produced by radial boreholes, enhance the mutual interference between radial boreholes, and guide fracture growth between radial boreholes. In hydraulic fracturing design, in order to reduce FIP and strengthen the interference between radial boreholes, the optimization design can be carried out by lowering intersection angle, increasing radius and number of boreholes, and reducing the depth difference between boreholes when the conditions permit. The research clarifies the interference between radial boreholes and provides the theoretical basis for optimizing radial boreholes layout in hydraulic fracturing guided by multi-radial boreholes.
\end{abstract}

\section{Introduction}

Radial drilling is a technology that is applied to accelerate the recovery of hydrocarbon reserves and reach reserves that are not economically exploitable with conventional completion techniques [1-3]. This technology, utilizing high-pressure water jet or mechanical drill bit, can forms several radial laterals, with a length between 10 and $100 \mathrm{~m}$ and borehole diameter between 25 and $50 \mathrm{~mm}[4,5]$. These radial laterals can penetrate the near well damage zone, augment wellborereservoir contact area, and connect the target reservoir area with a low producing degree.
However, due to the small diameter, radial drilling applied alone often has an unsatisfactory stimulation result in the reservoir with low permeability or undeveloped natural fracture. Thus, radial drilling-fracturing, the combination of the hydraulic fracturing and radial borehole, is proposed [6]. This technology integrates the merits both of hydraulic fracturing and radial drilling, guiding the hydraulic fracture toward the target area with radial borehole and, meanwhile, enhancing the wellbore-reservoir contact area significantly [7-10].

Up to now, many types of research have been conducted on the radial borehole layout patterns for different goals. As 


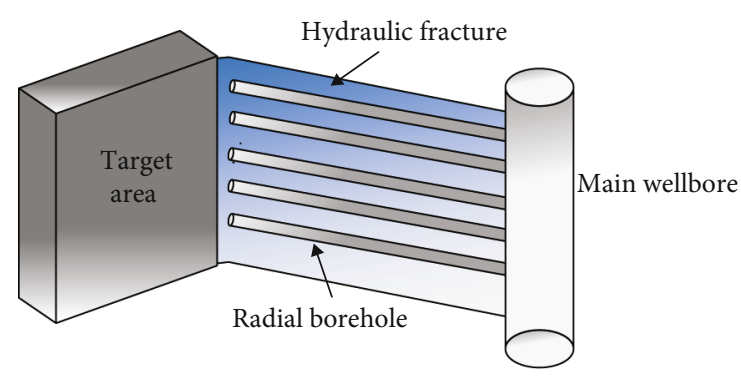

(a)

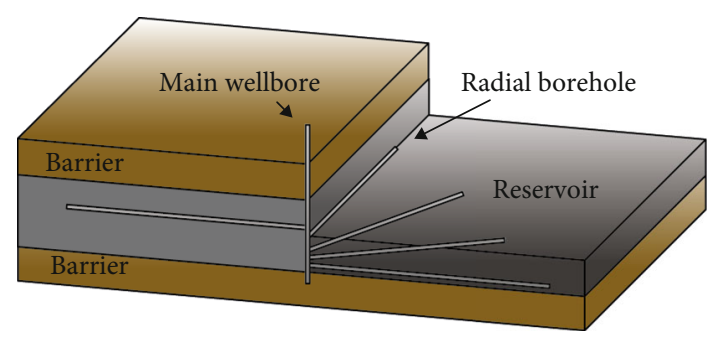

(b)

FIGURE 1: The layout pattern of radial boreholes. (a) Hydraulic fracturing guided by vertical multi-radial boreholes. (b) Tree-type hydraulic fracturing.

shown in Figure 1, Guo et al. [11] presented a layout method that radial borehole rows are vertically distributed along the main wellbore and extend toward the target development zone. This method can control hydraulic fractures to propagate along with the orientation of radial borehole row and communicate the target zone effectively. Besides, tree-type hydraulic fracturing technology $[12,13]$ adopts another classic layout pattern. Radial boreholes, protruding toward different orientations, have a radial tree-type distribution. Under the action of ground stress and water pressure, hydraulic fractures, initiating in individual radial boreholes, can extend to the adjacent boreholes and form a widespread hydraulic fracture network which can holistically enlarge drainage area and recovery.

Nevertheless, no matter which layout is taken, accurate prediction of fracture initiation pressure (FIP), a keystone parameter in the design and evaluation of hydraulic fracturing, is cardinal for a successful operation. Many pieces of researches on this issue have been conducted through experimental, analytical, and numerical methods. Ketterij et al. [14] experimentally demonstrated the influence of perforation azimuth on fracture initiation and propagation in case of a deviated wellbore. Hossain et al. [15] presented an analytical model to predict the fracture initiation pressure with and without perforations. Lhomme et al. [16] experimentally investigated the fracture initiation from an open-hole section. They found that fracture initiation is influenced by rock microstructure directly. Fallahzadeh et al. [17] developed a computer model of fracture initiation pressure for deviatedcased perforated wellbore and studied the near-wellbore stress distribution. Alekseenko et al. [18] established a boundary-element numerical model to stimulate fracture initiation from a perforated wellbore. Based on finite element method, Gong et al. [19] researched various parameters in radial drilling-fracturing and found that azimuth is most influenced on fracture initiation pressure, followed by length and diameter of the radial borehole. Liu et al. [20] established a generic model to predict fracture initiation from the radial borehole and analyzed the effect of preexisting weakness plane. Corresponding with three different in situ stress statues, they concluded three types of fracture initiation from radial borehole relatively, and the in situ stress regime and radial borehole orientation are most significant parameters influencing FIP for intact rock.
Currently, most fracture initiation analytical models of radial drilling-fracturing are based on the case of a single radial borehole and fail to consider the interference between multi-radial boreholes. Guo et al. established a theoretical mechanical model of hydraulic fracture guided by vertical multi-radial boreholes. However, they had focused on the calculation of stress distribution around an open main wellbore and failed to consider cased main wellbore and the fracture initiation from radial borehole. Besides, in fact that radial boreholes considered in their model have the same azimuth, their model cannot meet the demand of fracture initiation study for hydraulic fracturing that is induced by multiradial boreholes with different azimuths. Thus, an analytical model for fracture initiation from a particular radial borehole, considering the interference between multi-radial boreholes with different azimuths, is still blank in petroleum engineering.

In this paper, we establish a theoretical mechanical model for fracture initiation from one particular radial borehole under the action of two radial boreholes with different azimuths (basic research unit) for the first time. Then, based on this model, a serial of sensitivity analysis is taken by investigating the effects of different parameters including the intersection angle between radial boreholes, the depth difference, radius of the radial borehole, Biot coefficient, and the number of radial boreholes.

\section{Model Establishment}

In this part, considering the stress caused by wellbore pressure, fracturing fluid percolation effect, and in situ stress, we develop a model of two radial boreholes with arbitrary azimuths. Radial boreholes are considered as small open holes intersecting with the vertical main wellbore and yield independent additional stress fields. Next, the stress distribution along the wall of one particular radial borehole is available by coordinate transformation and stress superposition. Then, fracture initiation pressure of particular radial borehole is predicted based on the maximum tensile stress criterion.

2.1. Model Assumptions and Coordinate System. The following assumptions are made during the derivation of the analytical model: 


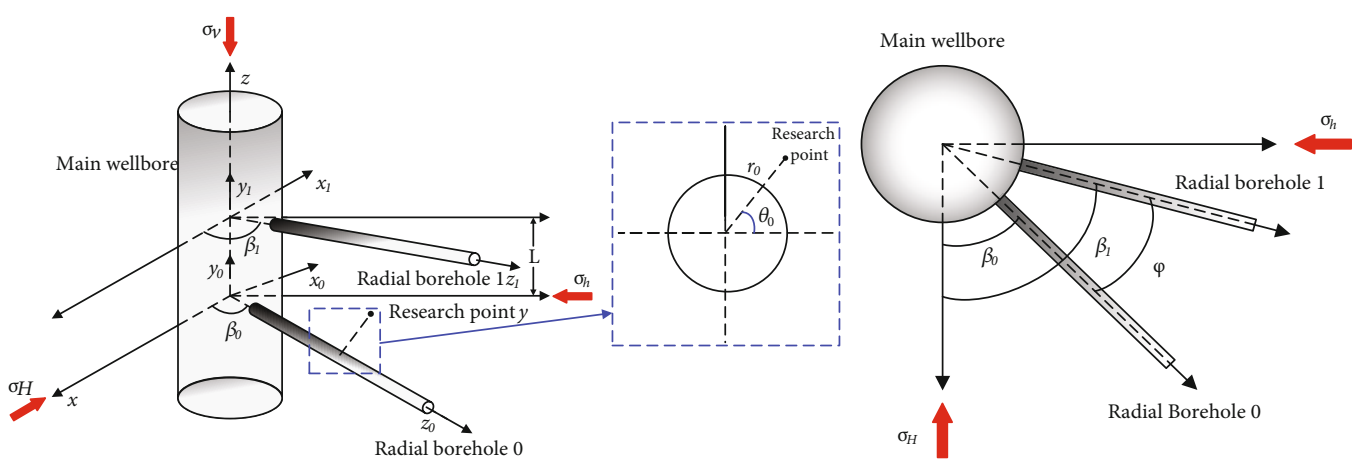

Figure 2: Schematic diagram of hydraulic fracturing guided by multi-radial boreholes.

(1) Formation rock is a homogeneous, isotropic, and linear elastic porous medium

(2) Microcracks inside rock have no influence

(3) The effect caused by the physicochemical action between fracturing fluid and formation rock is neglected

(4) Radial boreholes do not influence in situ stress

Coordinate systems established during derivation and the layout of radial boreholes are as shown in Figure 2. The radial borehole 0 is taken as the research object, and the model derivation is aimed at establishing an analytical model which can calculate the stress distribution along radial borehole 0 (RB0) under the effect of radial borehole 1 (RB1). In the process of model derivation, tensile stress is negative, and pressure stress is positive. A rectangular coordinate system $(x, y, z)$ is established in which the origin is located at the center of the wellbore cross-section, and $x$ axis, $y$ axis, and $z$ axis are aligned with the maximum horizontal stress, the minimum horizontal stress, and the main wellbore axis, relatively. Borehole coordinate systems are established. $z_{0}$ axis and $z_{1}$ axis are along the axis of two radial boreholes separately, while $y_{0}$ axis and $y_{1}$ axis are along the axis of the main wellbore. Thus, rectangular coordinate systems of the three boreholes, main wellbore and two radial boreholes, are $(x, y, z),\left(x_{0}, y_{0}\right.$, $\left.z_{0}\right)$, and $\left(x_{1}, y_{1}, z_{1}\right)$, and their cylindrical coordinate systems are $(r, \theta, z),\left(r_{0}, \theta_{0}, z_{0}\right)$, and $\left(r_{1}, \theta_{1}, z_{1}\right)$, respectively. $L$ is the depth difference between two radial boreholes. $\beta_{0}$ and $\beta_{1}$, the angle between the maximum horizontal stress direction and the axis of the radial borehole, are the azimuth angles of radial borehole 0 and radial borehole 1 , respectively. The intersection angle of radial boreholes, the angle between the projections of radial boreholes axes on the horizontal plane, is denoted with $\varphi$, which equals $\beta_{1}-\beta_{0} . r_{0}$ is the distance between research point and the axis of radial borehole 0 . Thus, the coordinate of research point where the stress is calculated is $\left(r_{0}, \theta_{0}, z_{0}\right)$ in $\left(r_{0}, \theta_{0}, z_{0}\right)$ coordinate systems.

2.2. Model Assumptions and Coordinate System. Due to the assumption that radial boreholes do not influence in situ stress, the in situ stress in rectangular coordinate system $(x$, $y, z)$ is:

$$
\left[\begin{array}{ccc}
\sigma_{\mathrm{xx}} & 0 & 0 \\
0 & \sigma_{\mathrm{yy}} & 0 \\
0 & 0 & \sigma_{\mathrm{zz}}
\end{array}\right]=\left[\begin{array}{ccc}
\sigma_{H} & 0 & 0 \\
0 & \sigma_{h} & 0 \\
0 & 0 & \sigma_{v}
\end{array}\right] \text {, }
$$

where $\sigma_{H}$ is the maximum horizontal in situ stress, $\mathrm{MPa} ; \sigma_{h}$ is the minimum horizontal in situ stress, $\mathrm{MPa} ; \sigma_{v}$ is the vertical in situ stress, $\mathrm{MPa}$; and $\sigma_{\mathrm{xx}}, \sigma_{\mathrm{yy}}$, and $\sigma_{\mathrm{zz}}$ are the normal stress components in the coordinate system $(x, y, z), \mathrm{MPa}$.

Combining with the existing formula, the stress distribution around the main wellbore caused by in situ stress can be attained in the coordinate system $(r, \theta, z)$ :

$$
\begin{aligned}
\sigma_{r}^{\text {In-Situ }}= & \frac{1}{2}\left(\sigma_{H}+\sigma_{h}\right)\left(1-\frac{R_{e}^{2}}{r^{2}}\right)+\frac{1}{2}\left(\sigma_{H}-\sigma_{h}\right) \\
& \cdot\left(1+\frac{3 R_{e}^{4}}{r^{4}}-\frac{4 R_{e}^{2}}{r^{2}}\right) \cos 2 \theta, \\
\sigma_{\theta}^{\text {In-Situ }}= & \frac{1}{2}\left(\sigma_{H}+\sigma_{h}\right)\left(1+\frac{R_{e}^{2}}{r^{2}}\right)-\frac{1}{2}\left(\sigma_{H}-\sigma_{h}\right) \\
& \cdot\left(1+\frac{3 R_{e}^{4}}{r^{4}}\right) \cos 2 \theta, \\
\sigma_{z}^{\text {In-Situ }}= & \sigma_{v}-2 v_{\mathrm{r}} \cos 2 \theta\left(\sigma_{H}-\sigma_{h}\right) \frac{R_{e}^{2}}{r^{2}}, \\
\tau_{r \theta}^{\text {In-Situ }}= & \frac{1}{2}\left(\sigma_{H}-\sigma_{h}\right)\left(1-\frac{3 R_{e}^{4}}{r^{4}}+\frac{2 R_{e}^{2}}{r^{2}}\right) \sin 2 \theta, \\
\tau_{\theta z}^{\text {In-Situ }}= & 0, \\
\tau_{r z}^{\text {In-Situ }=} & 0,
\end{aligned}
$$

where $\sigma_{r}, \sigma_{\theta}$, and $\sigma_{z}$ are the normal stress components in the cylindrical coordinate system $(r, \theta, z), \mathrm{MPa} ; \tau_{r \theta}, \tau_{\theta z}$, and $\tau_{r z}$ are the shear stress components in the cylindrical coordinate system $(r, \theta, z), \mathrm{MPa} ; v_{r}$ is the Poisson's ratio of rock; $R_{e}$ is the exterior radius of the main wellbore, $\mathrm{m}$; and $r$ is the distance between the axis of the main wellbore and any research point in formation, $\mathrm{m}$.

In order to attain the stress distribution along the radial borehole 0 , the stress components caused by in situ stress need a serial of transformations from the coordinate system $(r, \theta, z)$ into $(x, y, z),\left(x_{0}, y_{0}, z_{0}\right)$, and $\left(r_{0}, \theta_{0}, z_{0}\right)$, successively. 
First owing to the overlapping origin of the two coordinate systems, the stress components caused by in situ stress can be converted from $(r, \theta, z)$ coordinate system into $(x, y, z)$ coordinate system by the following formulas.

$$
\begin{aligned}
& {\left[\begin{array}{ccc}
\sigma_{x} & \tau_{x y} & \tau_{z x} \\
\tau_{x y} & \sigma_{y} & \tau_{y z} \\
\tau_{z x} & \tau_{y z} & \sigma_{z}
\end{array}\right]=\left[\begin{array}{ccc}
\cos \theta & -\sin \theta & 0 \\
\sin \theta & \cos \theta & 0 \\
0 & 0 & 1
\end{array}\right]\left[\begin{array}{ccc}
\sigma_{r} & \tau_{\theta r} & \tau_{z r} \\
\tau_{r \theta} & \sigma_{\theta} & \tau_{z \theta} \\
\tau_{r z} & \tau_{\theta z} & \sigma_{z}
\end{array}\right]} \\
& {\left[\begin{array}{ccc}
\cos \theta & \sin \theta & 0 \\
-\sin \theta & \cos \theta & 0 \\
0 & 0 & 1
\end{array}\right]} \\
& \sigma_{x}^{\text {In-Situ }}=\frac{x^{2}}{x^{2}+y^{2}}\left[\frac{1}{2}\left(\sigma_{H}+\sigma_{h}\right)\left(1-\frac{R_{e}{ }^{2}}{x^{2}+y^{2}}\right)+\frac{1}{2}\left(\sigma_{H}-\sigma_{h}\right)\right. \\
& \left.\cdot\left(1+\frac{3 R_{e}{ }^{4}}{\left(x^{2}+y^{2}\right)^{2}}-\frac{4 R_{e}{ }^{2}}{x^{2}+y^{2}}\right) \frac{x^{2}-y^{2}}{x^{2}+y^{2}}\right]+\frac{y^{2}}{x^{2}+y^{2}} \\
& \cdot\left[\frac{1}{2}\left(\sigma_{H}+\sigma_{h}\right)\left(1+\frac{R_{e}{ }^{2}}{x^{2}+y^{2}}\right)-\frac{1}{2}\left(\sigma_{H}-\sigma_{h}\right)\right. \\
& \left.\cdot\left(1+\frac{3 R_{e}{ }^{4}}{\left(x^{2}+y^{2}\right)^{2}}\right) \frac{x^{2}-y^{2}}{x^{2}+y^{2}}\right]-2 \frac{x^{2} y^{2}}{\left(x^{2}+y^{2}\right)^{2}} \\
& \cdot\left(\sigma_{H}-\sigma_{h}\right)\left(1-\frac{3 R_{e}^{4}}{\left(x^{2}+y^{2}\right)^{2}}+\frac{2 R_{e}^{2}}{x^{2}+y^{2}}\right)=F \text {, } \\
& \sigma_{y}^{\text {In-Situ }}=\frac{y^{2}}{x^{2}+y^{2}}\left[\frac{1}{2}\left(\sigma_{H}+\sigma_{h}\right)\left(1-\frac{R_{e}{ }^{2}}{x^{2}+y^{2}}\right)+\frac{1}{2}\left(\sigma_{H}-\sigma_{h}\right)\right. \\
& \left.\cdot\left(1+\frac{3 R_{e}{ }^{4}}{\left(x^{2}+y^{2}\right)^{2}}-\frac{4 R_{e}{ }^{2}}{x^{2}+y^{2}}\right) \frac{x^{2}-y^{2}}{x^{2}+y^{2}}\right]+\frac{x^{2}}{x^{2}+y^{2}} \\
& \text {. }\left[\frac{1}{2}\left(\sigma_{H}+\sigma_{h}\right)\left(1+\frac{R_{e}^{2}}{x^{2}+y^{2}}\right)-\frac{1}{2}\left(\sigma_{H}-\sigma_{h}\right)\right. \\
& \left.\cdot\left(1+\frac{3 R_{e}^{4}}{\left(x^{2}+y^{2}\right)^{2}}\right) \frac{x^{2}-y^{2}}{x^{2}+y^{2}}\right]+2 \frac{x^{2} y^{2}}{\left(x^{2}+y^{2}\right)^{2}} \\
& \cdot\left(\sigma_{H}-\sigma_{h}\right)\left(1-\frac{3 R_{e}^{4}}{\left(x^{2}+y^{2}\right)^{2}}+\frac{2 R_{e}^{2}}{x^{2}+y^{2}}\right)=K \text {, } \\
& \sigma_{z}^{\text {In-Situ }}=\sigma_{v}-2 v R_{e}^{2}\left(\sigma_{H}-\sigma_{h}\right) \frac{\left(x^{2}-y^{2}\right)}{\left(x^{2}+y^{2}\right)^{2}}=Q \text {, } \\
& \tau_{x y}^{\text {In-Situ }}=2 \frac{x y}{x^{2}+y^{2}}\left(\frac{x^{2}-y^{2}}{x^{2}+y^{2}}\right)\left(\sigma_{H}-\sigma_{h}\right) \\
& -\frac{x y}{x^{2}+y^{2}}\left(\sigma_{H}+\sigma_{h}\right)\left(\frac{R_{e}{ }^{2}}{x^{2}+y^{2}}\right)=T \text {, } \\
& \tau_{y z}^{\text {In-Situ }}=0, \\
& \tau_{z x}^{\text {In-Situ }}=0 .
\end{aligned}
$$

The expressions of $\sigma_{x}^{\text {In-Situ }}, \sigma_{y}^{\text {IP-Situ }}, \sigma_{z}^{\text {IP-Situ }}$, and $\tau_{x y}^{\text {IP-Situ }}$ are denoted with $F, K, Q$, and $T$, respectively, for the facility of derivation. Second, the coordinate transformation expression from $(x, y, z)$ coordinate system into $\left(x_{0}, y_{0}, z_{0}\right)$ coordinate system can be written as follows.

$$
\begin{aligned}
{\left[\begin{array}{ccc}
\sigma_{x_{0}} & \tau_{x_{0} y_{0}} & \tau_{z_{0} x_{0}} \\
\tau_{x_{0} y_{0}} & \sigma_{y_{0}} & \tau_{y_{0} z_{0}} \\
\tau_{z_{0} x_{0}} & \tau_{y_{0} z_{0}} & \sigma_{z_{0}}
\end{array}\right]=} & {\left[\begin{array}{ccc}
-\sin \beta_{0} & \cos \beta_{0} & 0 \\
0 & 0 & 1 \\
\cos \beta_{0} & \sin \beta_{0} & 0
\end{array}\right] } \\
& {\left[\begin{array}{ccc}
\sigma_{x} & \tau_{x y} & \tau_{z x} \\
\tau_{x y} & \sigma_{y} & \tau_{y z} \\
\tau_{z x} & \tau_{y z} & \sigma_{z}
\end{array}\right] } \\
& \cdot\left[\begin{array}{ccc}
-\sin \beta_{0} & 0 & \cos \beta_{0} \\
\cos \beta_{0} & 0 & \sin \beta_{0} \\
0 & 1 & 0
\end{array}\right] .
\end{aligned}
$$

Then, the stress component transformation from $\left(x_{0}, y_{0}\right.$, $\left.z_{0}\right)$ coordinate system into $\left(r_{0}, \theta_{0}, z_{0}\right)$ coordinate system can be conducted as the formula.

$$
\begin{aligned}
{\left[\begin{array}{ccc}
\sigma_{r_{0}} & \tau_{\theta_{0} r_{0}} & \tau_{z_{0} r_{0}} \\
\tau_{r_{0} \theta_{0}} & \sigma_{\theta_{0}} & \tau_{z_{0} \theta_{0}} \\
\tau_{r_{0} z_{0}} & \tau_{\theta_{0} z_{0}} & \sigma_{z_{0}}
\end{array}\right]=} & {\left[\begin{array}{ccc}
\cos \theta_{0} & \sin \theta_{0} & 0 \\
-\sin \theta_{0} & \cos \theta_{0} & 0 \\
0 & 0 & 1
\end{array}\right] } \\
& \cdot\left[\begin{array}{ccc}
\sigma_{x_{0}} & \tau_{x_{0} y_{0}} & \tau_{z_{0} x_{0}} \\
\tau_{x_{0} y_{0}} & \sigma_{y_{0}} & \tau_{y_{0} z_{0}} \\
\tau_{z_{0} x_{0}} & \tau_{y_{0} z_{0}} & \sigma_{z_{0}}
\end{array}\right] \\
& \cdot\left[\begin{array}{cccc}
\cos \theta_{0} & -\sin \theta_{0} & 0 \\
\sin \theta_{0} & \cos \theta_{0} & 0 \\
0 & 0 & 1
\end{array}\right] .
\end{aligned}
$$

Based on the above formulas, the final expression of stress components caused by in situ stress can be obtained in $\left(r_{0}, \theta_{0}\right.$, $z_{0}$ ) coordinate system.

$$
\begin{aligned}
& \sigma_{r_{0}}^{\text {In-Situ }}=\cos ^{2} \theta_{0}\left(\sin ^{2} \beta_{0} F+\cos ^{2} \beta_{0} K-2 \sin \beta_{0} \cos \beta_{0} T\right)+Q \sin ^{2} \theta_{0}, \\
& \sigma_{\theta_{0}}^{\text {In-Situ }}=\sin ^{2} \theta_{0}\left(\sin ^{2} \beta_{0} F+\cos ^{2} \beta_{0} K-2 \sin \beta_{0} \cos \beta_{0} T\right)+Q \cos ^{2} \theta_{0}, \\
& \sigma_{z_{0}}^{\text {In-Situ }}=\cos ^{2} \beta_{0} F+\sin ^{2} \beta_{0} K+2 \sin \beta_{0} \cos \beta_{0} T, \\
& \tau_{r_{0} \theta_{0}}^{\text {In-Situ }}=\left(Q-\sin ^{2} \beta_{0} F-\cos ^{2} \beta_{0} K+2 \sin \beta_{0} \cos \beta_{0} T\right) \sin \theta_{0} \cos \theta_{0}, \\
& \tau_{\theta_{0} z_{0}}^{\text {In-Situ }}=-\sin \theta_{0}\left(\left(\cos ^{2} \beta_{0}-\sin ^{2} \beta_{0}\right) T+\sin \beta_{0} \cos \beta_{0}(K-F)\right), \\
& \tau_{z_{0} r_{0}}^{\text {In-Situ }}=\cos \theta_{0}\left(\left(\cos ^{2} \beta_{0}-\sin ^{2} \beta_{0}\right) T+\sin \beta_{0} \cos \beta_{0}(K-F)\right) .
\end{aligned}
$$


The above some components are shown in the formula.

$$
\begin{aligned}
& x=\cos \beta_{0}\left(z_{0}-r_{0} \cos \theta_{0} \tan \beta_{0}\right), \\
& y=\frac{r_{0} \cos \theta_{0}}{\cos \beta_{0}}+\sin \beta_{0}\left(z_{0}-r_{0} \cos \theta_{0} \tan \beta_{0}\right), \\
& z=r_{0} \sin \theta_{0} .
\end{aligned}
$$

2.3. Stress Caused by Wellbore Pressure. When fracturing fluid is pumped into wellbore, the internal pressure, $P_{w}$, is acting radially on the wall of the wellbore and generates stress field around the wellbore. Unlike radial boreholes, the main wellbore is cased, and the internal pressure, $P_{w}$, only can be delivered partially to the rock due to the high rigidity of the casing. Thus, the main wellbore and radial boreholes need to be investigated separately.

2.3.1. Stress Caused by Wellbore Pressure. Considering Young's modulus of the casing is much higher than rock, and Young's modulus of cement sheath and rock are in the same magnitude, the influence of cement sheath can be ignored, and the effect of casing should be considered. The stress generated by the internal pressure of the main wellbore can be written as follows in the cylindrical coordinate system $(r, \theta, z)$, considering the effect of casing [21].

$$
\begin{aligned}
\sigma_{r}^{\mathrm{IP}-\mathrm{MB}} & =\frac{R_{e}^{2}}{r^{2}} P_{i}, \\
\sigma_{\theta}^{\mathrm{IP}-\mathrm{MB}} & =-\frac{R_{e}^{2}}{r^{2}} P_{i} .
\end{aligned}
$$

Of which:

$P_{i}=\frac{1+v_{c}}{E_{c}} \frac{2\left(1-v_{c}\right)}{R_{e}^{2}-R_{i}^{2}} R_{i}^{2} P_{w} /\left[\frac{1+v_{r}}{E_{r}}+\frac{1+v_{c}}{E_{c}} \frac{R_{i}^{2}+\left(1-2 v_{c}\right) R_{e}^{2}}{R_{e}^{2}-R_{i}^{2}}\right]$,

where $v_{c}$ is Poisson's ratio of the casing; $v_{r}$ is Poisson's ratio of rock; $E_{r}$ is Young's modulus of rock, GPa; $E_{c}$ is Young's modulus of the casing, $\mathrm{GPa}$; and $R_{i}$ is the internal radius of the casing, $\mathrm{m}$.

Based on the coordinate transformation matrix (3), the stress expressions caused by main wellbore internal pressure can be available in $(x, y, z)$ coordinate system.

$$
\begin{gathered}
\sigma_{x}^{\mathrm{IP}-\mathrm{MB}}=\frac{R_{e}^{2} P_{i}\left(x^{2}-y^{2}\right)}{\left(x^{2}+y^{2}\right)^{2}}=M, \\
\sigma_{y}^{\mathrm{IP}-\mathrm{MB}}=-\frac{R_{e}^{2} P_{i}\left(x^{2}-y^{2}\right)}{\left(x^{2}+y^{2}\right)^{2}}=-M, \\
\sigma_{z}^{\mathrm{IP}-\mathrm{MB}}=0, \\
\tau_{x y}^{\mathrm{IP}-\mathrm{MB}}=\frac{2 R_{e}^{2} P_{i} x y}{\left(x^{2}+y^{2}\right)^{2}}=N,
\end{gathered}
$$

$$
\tau_{y z}^{\mathrm{IP}-\mathrm{MB}}=0, \tau_{z x}^{\mathrm{IP}-\mathrm{MB}}=0 .
$$

The expressions of $\sigma_{x}^{\mathrm{IP}-\mathrm{MB}}, \sigma_{y}^{\mathrm{IP}-\mathrm{MB}}$, and $\sigma_{x y}^{\mathrm{IP}-\mathrm{MB}}$ are denoted with $M,-M$, and $N$ separately for facilitating model derivation. Similar to in situ stress, the terms of the stress components caused by main wellbore internal pressure in the $\left(r_{0}\right.$, $\left.\theta_{0}, z_{0}\right)$ coordinate system can be obtained through a serial of conversion according to formulas (5) and (6).

$$
\begin{aligned}
& \sigma_{r_{0}}^{\mathrm{IP}-\mathrm{MB}}=\cos ^{2} \theta_{0}\left(\left(\sin ^{2} \beta_{0}-\cos ^{2} \beta_{0}\right) M-2 \sin \beta_{0} \cos \beta_{0} N\right), \\
& \sigma_{\theta_{0}}^{\mathrm{IP}-\mathrm{MB}}=\sin ^{2} \theta_{0}\left(\left(\sin ^{2} \beta_{0}-\cos ^{2} \beta_{0}\right) M-2 \sin \beta_{0} \cos \beta_{0} N\right), \\
& \sigma_{z_{0}}^{\mathrm{IP}-\mathrm{MB}}=\left(\cos ^{2} \beta_{0}-\sin ^{2} \beta_{0}\right) M+2 \sin \beta_{0} \cos \beta_{0} N, \\
& \tau_{r_{0} \theta_{0}}^{\mathrm{IP}-\mathrm{MB}}=-\sin \theta_{0} \cos \theta_{0}\left(\left(\sin ^{2} \beta_{0}-\cos ^{2} \beta_{0}\right) M-2 \sin \beta_{0} \cos \beta_{0} N\right), \\
& \tau_{\theta_{0} z_{0}}^{\mathrm{IP}-\mathrm{MB}}=-\sin \theta_{0}\left(\left(\cos ^{2} \beta_{0}-\sin ^{2} \beta_{0}\right) N-2 \sin \beta_{0} \cos \beta_{0} M\right), \\
& \tau_{z_{0} r_{0}}^{\mathrm{IP}-\mathrm{MB}}=\cos \theta_{0}\left(\left(\cos ^{2} \beta_{0}-\sin ^{2} \beta_{0}\right) N-2 \sin \beta_{0} \cos \beta_{0} M\right) .
\end{aligned}
$$

The above some components are shown in the formula.

$$
\begin{aligned}
& x=\cos \beta_{0}\left(z_{0}-r_{0} \cos \theta_{0} \tan \beta_{0}\right), \\
& y=\frac{r_{0} \cos \theta_{0}}{\cos \beta_{0}}+\sin \beta_{0}\left(z_{0}-r_{0} \cos \theta_{0} \tan \beta_{0}\right), \\
& z=r_{0} \sin \theta_{0} .
\end{aligned}
$$

2.3.2. Stress Caused by Internal Pressure of Radial Borehole 0. Compared with the main borehole, the influence of casing is not considered in radial boreholes because radial boreholes are open boreholes. Thus, the stress components in $\left(r_{0}, \theta_{0}\right.$, $z_{0}$ ) coordinate system caused by the internal pressure of radial borehole 0 can be attained directly.

$$
\begin{gathered}
\sigma_{r_{0}}^{\mathrm{IP}-\mathrm{RB} 0}=\frac{R_{0}^{2}}{r_{0}^{2}} P_{w}, \\
\sigma_{\theta_{0}}^{\mathrm{IP}-\mathrm{RB} 0}=-\frac{R_{0}^{2}}{r_{0}^{2}} P_{w},
\end{gathered}
$$

where $R_{0}$ is the radius of radial borehole $0, \mathrm{~m}$, and $P_{w}$ is the internal pressure, $\mathrm{MPa}$.

2.3.3. Stress Caused by Internal Pressure of Radial Borehole 1. Similar to radial borehole 0 , the stress caused by the internal pressure of radial borehole 1 can be obtained in the coordinate system $\left(\mathrm{r}_{1}, \theta_{1}, z_{1}\right)$.

$$
\begin{gathered}
\sigma_{r_{1}}^{\mathrm{IP}-\mathrm{RB} 1}=\frac{R_{1}^{2}}{r_{1}^{2}} P_{w}, \\
\sigma_{\theta_{1}}^{\mathrm{IP}-\mathrm{RB} 1}=-\frac{R_{1}^{2}}{r_{1}^{2}} P_{w},
\end{gathered}
$$


where $R_{1}$ is the radius of radial borehole $1, \mathrm{~m}$, and $r_{1}$ is the distance between the axis of radial borehole 1 and any research point in formation, $m$.

Next, the stress components are converted from $\left(r_{1}, \theta_{1}\right.$, $\left.z_{1}\right)$ coordinate system into $\left(x_{1}, y_{1}, z_{1}\right)$ coordinate system with coordinate transformation matrix (3).

$$
\begin{aligned}
& \sigma_{x_{1}}^{\mathrm{IP}-\mathrm{RB} 1}=\frac{R_{1}^{2} P_{w}\left(x_{1}^{2}-y_{1}^{2}\right)}{\left(x_{1}^{2}+y_{1}^{2}\right)^{2}}=M_{1}, \\
& \sigma_{y_{1}}^{\mathrm{IP}-\mathrm{RB} 1}=-\frac{R_{1}^{2} P_{w}\left(x_{1}^{2}-y_{1}^{2}\right)}{\left(x_{1}^{2}+y_{1}^{2}\right)^{2}}=-M_{1}, \\
& \sigma_{z_{1}}^{\mathrm{IP}-\mathrm{RB} 1}=0, \\
& \tau_{x_{1} y_{1}}^{\mathrm{IP}-\mathrm{RB} 1}=\frac{2 R_{1}^{2} P_{w} x_{1} y_{1}}{\left(x_{1}^{2}+y_{1}^{2}\right)^{2}}=N_{1}, \\
& \tau_{y_{1} z_{1}}^{\mathrm{IP}-\mathrm{RB} 1}=0, \\
& \tau_{z_{1} x_{1}}^{\mathrm{IP}-\mathrm{RB} 1}=0 .
\end{aligned}
$$

The expressions of $\sigma_{x_{1}}^{\mathrm{IP}-\mathrm{RB} 1}, \sigma_{y_{1}}^{\mathrm{IP}-\mathrm{RB} 1}$, and $\sigma_{x_{1} y_{1}}^{\mathrm{IP}-\mathrm{RB} 1}$ are written as $M_{1},-M_{1}$, and $N_{1}$, respectively. Continue to convert the stress components from $\left(x_{1}, y_{1}, z_{1}\right)$ coordinate system into $\left(x_{0}, y_{0}, z_{0}\right)$ coordinate system by the following coordinate transformation matrix (17).

$$
\begin{aligned}
{\left[\begin{array}{ccc}
\sigma_{x_{0}} & \tau_{x_{0} y_{0}} & \tau_{z_{0} x_{0}} \\
\tau_{x_{0} y_{0}} & \sigma_{y_{0}} & \tau_{y_{0} z_{0}} \\
\tau_{z_{0} x_{0}} & \tau_{y_{0} z_{0}} & \sigma_{z_{0}}
\end{array}\right]=} & {\left[\begin{array}{ccc}
\cos \varphi & 0 & \sin \varphi \\
0 & 1 & 0 \\
-\sin \varphi & 0 & \cos \varphi
\end{array}\right]\left[\begin{array}{ccc}
\sigma_{x_{1}} & \tau_{x_{1} y_{1}} & \tau_{z_{1} x_{1}} \\
\tau_{x_{1} y_{1}} & \sigma_{y_{1}} & \tau_{y_{1} z_{1}} \\
\tau_{z_{1} x_{1}} & \tau_{y_{1} z_{1}} & \sigma_{z_{1}}
\end{array}\right] } \\
& \cdot\left[\begin{array}{ccc}
\cos \varphi & 0 & -\sin \varphi \\
0 & 1 & 0 \\
\sin \varphi & 0 & \cos \varphi
\end{array}\right] .
\end{aligned}
$$

Then, combining the expressions of stress components in $\left(x_{0}, y_{0}, z_{0}\right)$ coordinate system and formula (6), the final expressions of stress components caused by the internal pressure of radial borehole 1 can be achieved in $\left(r_{0}, \theta_{0}, z_{0}\right)$ coordinate system.

$$
\begin{gathered}
\sigma_{r_{0}}^{\mathrm{IP}-\mathrm{RB} 1}=\left(\cos ^{2} \theta_{0} \cos ^{2} \varphi-\sin ^{2} \theta_{0}\right) M_{1}+2 \sin \theta_{0} \cos \theta_{0} \cos \varphi N_{1}, \\
\sigma_{\theta_{0}}^{\mathrm{IP}-\mathrm{RB} 1}=\left(\sin ^{2} \theta_{0} \cos ^{2} \varphi-\cos ^{2} \theta_{0}\right) M_{1}-2 \sin \theta_{0} \cos \theta_{0} \cos \varphi N_{1}, \\
\sigma_{z_{0}}^{\mathrm{IP}-\mathrm{RB} 1}=\sin ^{2} \varphi M_{1}, \\
\tau_{r_{0} \theta_{0}}^{\mathrm{IP}-\mathrm{RB} 1}=-\left(1+\cos ^{2} \varphi\right) \sin \theta_{0} \cos \theta_{0} M_{1}+\left(\cos ^{2} \theta_{0}-\sin ^{2} \theta_{0}\right) \cos \varphi N_{1}, \\
\tau_{\theta_{0} z_{0}}^{\mathrm{IP}-\mathrm{RB} 1}=\sin \varphi \cos \varphi \sin \theta_{0} M_{1}-\sin \varphi \cos \theta_{0} N_{1}, \\
\tau_{z_{0} r_{0}}^{\mathrm{IP}-\mathrm{RB} 1}=-\sin \varphi \cos \varphi \cos \theta_{0} M_{1}-\sin \varphi \sin \theta_{0} N_{1} .
\end{gathered}
$$

The above some components are shown in the formula.

$$
\begin{aligned}
& x_{1}=\cos \varphi\left(r_{0} \cos \theta_{0}-z_{0} \tan \varphi\right), \\
& y_{1}=r_{0} \sin \theta_{0}-L, \\
& z_{1}=\frac{z_{0}}{\cos \varphi}+\sin \varphi\left(r_{0} \cos \theta_{0}-z_{0} \tan \varphi\right) .
\end{aligned}
$$

2.4. Stress Caused by Fracturing Fluid Percolation. The fracture fluid will permeate into formation and increase the pore fluid pressure around borehole under the high wellbore pressure during the hydraulic fracture operation. The fracturing fluid percolation of radial boreholes is taken into account, and the fracturing fluid percolation of the cased main wellbore can be neglected.

2.4.1. Stress Caused by Fracturing Fluid Percolation of Radial Borehole 0. Assuming that fluid flow in formation is radial flow and follows Darcy's law, the stress caused by fracturing fluid percolation of radial borehole 0 can be provided in $\left(r_{0}\right.$, $\left.\theta_{0}, z_{0}\right)$ coordinate system according to former research [22].

$$
\begin{aligned}
& \sigma_{r_{0}}^{\mathrm{FP}-\mathrm{RB} 0}=A-\frac{B_{0}}{r_{0}{ }^{2}}, \\
& \sigma_{\theta_{0}}^{\mathrm{FP}-\mathrm{RB} 0}=A+\frac{B_{0}}{r_{0}^{2}}, \\
& \sigma_{z_{0}}^{\mathrm{FP}-\mathrm{RB} 0}=C .
\end{aligned}
$$

Of which:

$$
\begin{gathered}
A=\delta\left(P_{w}-P_{p}\right)\left(\frac{\varepsilon\left(1-2 v_{r}\right)}{2\left(1-v_{r}\right)}-\phi\right), \\
B_{0}=\delta R_{0}^{2}\left(P_{w}-P_{p}\right) \frac{\varepsilon\left(1-2 v_{r}\right)}{2\left(1-v_{r}\right)}, \\
C=\delta\left[\frac{\varepsilon\left(1-2 v_{r}\right)}{1-v_{r}}-\phi\right]\left(P_{w}-P_{p}\right),
\end{gathered}
$$

where $P_{p}$ is the initial pore fluid pressure, $\mathrm{MPa} \delta \delta$ is the permeability coefficient; $\phi$ is the porosity of formation; $\varepsilon$ is the Biot coefficient, $\varepsilon=1-C_{r} / C_{b}$; and $C_{r}$ and $C_{b}$ are the compression rates of the rock skeleton and volume, respectively.

2.4.2. Stress Caused by Fracturing Fluid Percolation of Radial Borehole 1. The stress components yielded by fracturing fluid percolation of radial borehole 1 and expression of stress components can be obtained directly in the cylindrical coordinate system $\left(r_{1}, \theta_{1}, z_{1}\right)$.

$$
\begin{aligned}
& \sigma_{r_{1}}^{\mathrm{FP}-\mathrm{RB} 1}=A-\frac{B_{1}}{r_{1}^{2}}, \\
& \sigma_{\theta_{1}}^{\mathrm{FP}-\mathrm{RB} 1}=A+\frac{B_{1}}{r_{1}^{2}}, \\
& \sigma_{z_{1}}^{\mathrm{FP}-\mathrm{RB} 1}=C .
\end{aligned}
$$


Of which:

$$
B_{1}=\delta R_{1}^{2}\left(P_{w}-P_{p}\right) \frac{\varepsilon\left(1-2 v_{r}\right)}{2\left(1-v_{r}\right)}
$$

The stress components can be converted into $\left(x_{1}, y_{1}, z_{1}\right)$ coordinate system by coordinate transformation matrix (3), and the expressions of $\sigma_{x_{1}}^{\mathrm{FP}-\mathrm{RB} 1}, \sigma_{y_{1}}^{\mathrm{FP}-\mathrm{RB} 1}$, and $\sigma_{x_{1} y_{1}}^{\mathrm{FP}-\mathrm{RB} 1}$ are denoted as $A-G_{1}, A+G_{1}$, and $-H_{1}$, respectively, for the facility of the following derivation.

$$
\begin{aligned}
& \sigma_{x_{1}}^{\mathrm{FP}-\mathrm{RB} 1}=A-\frac{B_{1}\left(x_{1}^{2}-y_{1}^{2}\right)}{\left(x_{1}^{2}+y_{1}^{2}\right)^{2}}=A-G_{1}, \\
& \sigma_{y_{1}}^{\mathrm{FP}-\mathrm{RB} 1}=A+\frac{B_{1}\left(x_{1}^{2}-y_{1}^{2}\right)}{\left(x_{1}^{2}+y_{1}^{2}\right)^{2}}=A+G_{1}, \\
& \sigma_{z_{1}}^{\mathrm{FP}-\mathrm{RB} 1}=C, \\
& \tau_{x_{1} y_{1}}^{\mathrm{FP}-\mathrm{RB} 1}=-\frac{2 B_{1} x_{1} y_{1}}{\left(x_{1}^{2}+y_{1}^{2}\right)^{2}}=-H_{1}, \\
& \tau_{y_{1} z_{1}}^{\mathrm{FP}-\mathrm{RB} 1}=0, \\
& \tau_{z_{1} x_{1}}^{\mathrm{FP}-\mathrm{RB} 1}=0 .
\end{aligned}
$$

Through a serial of transformations which are same with the treatment of stress generated by the internal pressure of radial borehole 1, the final expressions of stress components caused by fracturing fluid percolation of radial borehole 1 can be achieved in the coordinate system $\left(r_{0}, \theta_{0}, z_{0}\right)$ based on formulas (17) and (6).

$$
\begin{aligned}
\sigma_{r_{0}}^{\mathrm{FP}-\mathrm{RB} 1}= & \cos ^{2} \theta_{0}\left(\cos ^{2} \varphi\left(A-G_{1}\right)+\sin ^{2} \varphi C\right)+\sin ^{2} \theta_{0}\left(A+G_{1}\right) \\
& -2 \cos \varphi \sin \theta_{0} \cos \theta_{0} H_{1}, \\
\sigma_{\theta_{0}}^{\mathrm{FP}-\mathrm{RB} 1}= & \sin ^{2} \theta_{0}\left(\cos ^{2} \varphi\left(A-G_{1}\right)+\sin ^{2} \varphi C\right)+\cos ^{2} \theta_{0}\left(A+G_{1}\right) \\
& +2 \cos \varphi \sin \theta_{0} \cos \theta_{0} H_{1}, \\
\sigma_{z_{0}}^{\mathrm{FP}-\mathrm{RB} 1}= & \sin ^{2} \varphi\left(A-G_{1}\right)+\cos ^{2} \varphi C, \\
\tau_{r_{0} \theta_{0}}^{\mathrm{FP}-\mathrm{RB} 1}= & \left(\left(A+G_{1}\right)-\left(\cos ^{2} \varphi\left(A-G_{1}\right)+\sin ^{2} \varphi C\right)\right) \\
& \cdot \sin \theta_{0} \cos \theta_{0}-\cos \varphi\left(\cos ^{2} \theta_{0}-\sin ^{2} \theta_{0}\right) H_{1}, \\
\tau_{\theta_{0} z_{0}}^{\mathrm{FP}-\mathrm{RB} 1}=- & \sin \varphi \cos \varphi \sin \theta_{0}\left(C-\left(A-G_{1}\right)\right)+\sin \varphi \cos \theta_{0} H_{1}, \\
\tau_{z_{0} r_{0}}^{\mathrm{FP}-\mathrm{RB} 1}= & \sin \varphi \cos \varphi \cos \theta_{0}\left(C-\left(A-G_{1}\right)\right)+\sin \varphi \sin \theta_{0} H_{1} .
\end{aligned}
$$

The above some components are shown in the formula.

$$
\begin{aligned}
& x_{1}=\cos \varphi\left(r_{0} \cos \theta_{0}-z_{0} \tan \varphi\right), \\
& y_{1}=r_{0} \sin \theta_{0}-L, \\
& z_{1}=\frac{z_{0}}{\cos \varphi}+\sin \varphi\left(r_{0} \cos \theta_{0}-z_{0} \tan \varphi\right) .
\end{aligned}
$$

2.5. Total Stress Components around the Radial Borehole 0. All stress components generated by in situ stress, internal pressure, and fracturing fluid percolation of all boreholes have been obtained separately and converted into $\left(r_{0}, \theta_{0}, z_{0}\right.$ ) coordinate system through the above derivation. According to stress superposition principle, the total stress components around the radial borehole 0 can be obtained in $\left(r_{0}, \theta_{0}, z_{0}\right)$ coordinate system as follow.

$$
\begin{aligned}
& \sigma_{r_{0}}^{\text {Total }}=\sigma_{r_{0}}^{\text {In-Situ }}+\sigma_{r_{0}}^{\mathrm{IP}-\mathrm{MB}}+\sigma_{r_{0}}^{\mathrm{IP}-\mathrm{RB} 0}+\sigma_{r_{0}}^{\mathrm{FP}-\mathrm{RB} 0}+\sigma_{r_{0}}^{\mathrm{IP}-\mathrm{RB} 1}+\sigma_{r_{0}}^{\mathrm{FP}-\mathrm{RB} 1}, \\
& \sigma_{\theta_{0}}^{\text {Total }}=\sigma_{\theta_{0}}^{\mathrm{In}-\mathrm{Situ}}+\sigma_{\theta_{0}}^{\mathrm{IP}-\mathrm{MB}}+\sigma_{\theta_{0}}^{\mathrm{IP}-\mathrm{RB} 0}+\sigma_{\theta_{0}}^{\mathrm{FP}-\mathrm{RB} 0}+\sigma_{\theta_{0}}^{\mathrm{IP}-\mathrm{RB} 1}+\sigma_{\theta_{0}}^{\mathrm{FP}-\mathrm{RB} 1}, \\
& \sigma_{z_{0}}^{\text {Total }}=\sigma_{z_{0}}^{\mathrm{In}-\mathrm{Situ}}+\sigma_{z_{0}}^{\mathrm{IP}-\mathrm{MB}}+\sigma_{z_{0}}^{\mathrm{IP}-\mathrm{RB} 0}+\sigma_{z_{0}}^{\mathrm{FP}-\mathrm{RB} 0}+\sigma_{z_{0}}^{\mathrm{IP}-\mathrm{RB} 1}+\sigma_{z_{0}}^{\mathrm{FP}-\mathrm{RB} 1}, \\
& \tau_{r_{0} \theta_{0}}^{\text {Total }}=\sigma_{r_{0} \theta_{0}}^{\mathrm{In}-\mathrm{Situ}}+\sigma_{r_{0} \theta_{0}}^{\mathrm{IP}-\mathrm{MB}}+\sigma_{r_{0} \theta_{0}}^{\mathrm{IP}-\mathrm{RB} 0}+\sigma_{r_{0} \theta_{0}}^{\mathrm{FP}-\mathrm{RB} 0}+\sigma_{r_{0} \theta_{0}}^{\mathrm{IP}-\mathrm{RB} 1}+\sigma_{r_{0} \theta_{0}}^{\mathrm{FP}-\mathrm{RB} 1}, \\
& \tau_{\theta_{0} z_{0}}^{\text {Total }}=\sigma_{\theta_{0} z_{0}}^{\mathrm{In}-\mathrm{Situ}}+\sigma_{\theta_{0} z_{0}}^{\mathrm{IP}-\mathrm{MB}}+\sigma_{\theta_{0} z_{0}}^{\mathrm{IP}-\mathrm{RB} 0}+\sigma_{\theta_{0} z_{0}}^{\mathrm{FP}-\mathrm{RB} 0}+\sigma_{\theta_{0} z_{0}}^{\mathrm{IP}-\mathrm{R} 1}+\sigma_{\theta_{0} z_{0}}^{\mathrm{FP}-\mathrm{RB} 1}, \\
& \tau_{z_{0} r_{0}}^{\text {Total }}=\sigma_{z_{0} r_{0}}^{\mathrm{In}-\mathrm{Situ}}+\sigma_{z_{0} r_{0}}^{\mathrm{IP}-\mathrm{MB}}+\sigma_{z_{0} r_{0}}^{\mathrm{IP}-\mathrm{RB} 0}+\sigma_{z_{0} r_{0}}^{\mathrm{FP}-\mathrm{RB} 0}+\sigma_{z_{0} r_{0}}^{\mathrm{IP}-\mathrm{R} 1}+\sigma_{z_{0} r_{0}}^{\mathrm{FP}-\mathrm{RB} 1} .
\end{aligned}
$$

2.6. Fracture Initiation from Radial Borehole 0. There are many fracture criteria used in predicting fracture initiation, such as maximum tensile stress criterion, maximum tensile strain criterion, Tresca criterion, and Von Mises criterion. The maximum tensile stress criterion is chosen as the prediction principle in this paper. The three principal stresses can be calculated by formula (28) according to elasticity mechanics theory.

$$
\begin{aligned}
& \sigma_{1}=\sigma_{r_{0}}^{\text {Total }}, \\
& \sigma_{2}=\frac{1}{2}\left[\left(\sigma_{\theta_{0}}^{\text {Total }}+\sigma_{z_{0}}^{\text {Total }}\right)+\sqrt{\left(\sigma_{\theta_{0}}^{\text {Total }}-\sigma_{z_{0}}^{\text {Total }}\right)^{2}+4\left(\tau_{\theta_{0} z_{0}}^{\text {Total }}\right)^{2}}\right], \\
& \sigma_{3}=\frac{1}{2}\left[\left(\sigma_{\theta_{0}}^{\text {Total }}+\sigma_{z_{0}}^{\text {Total }}\right)-\sqrt{\left(\sigma_{\theta_{0}}^{\text {Total }}-\sigma_{z_{0}}^{\text {Total }}\right)^{2}+4\left(\tau_{\theta_{0} z_{0}}^{\text {Total }}\right)^{2}}\right] .
\end{aligned}
$$

In terms of the porous medium, the total stress should be substituted by effective stress. For the convention that pressure stress is defined as positive, the maximum tensile stress of research point $\left(r_{0}, \theta_{0}, z_{0}\right)$ can be written as formula (29).

$$
\sigma_{t}\left(r_{0}, \theta_{0}, z_{0}\right)=-\left[\sigma_{3}\left(r_{0}, \theta_{0}, z_{0}\right)-P_{p}\right] .
$$

The condition of fracture initiation is given as:

$$
\sigma_{t}\left(r_{0}, \theta_{0}, z_{0}\right)>\sigma_{T}
$$

where $\sigma_{T}$ is the tensile strength of rock, MPa.

\section{Case Calculation and Sensitivity Analysis}

To study fracture initiation from radial borehole $0, r_{0}$ takes the value of $R_{0}$ to calculate the stress on the wall of borehole 

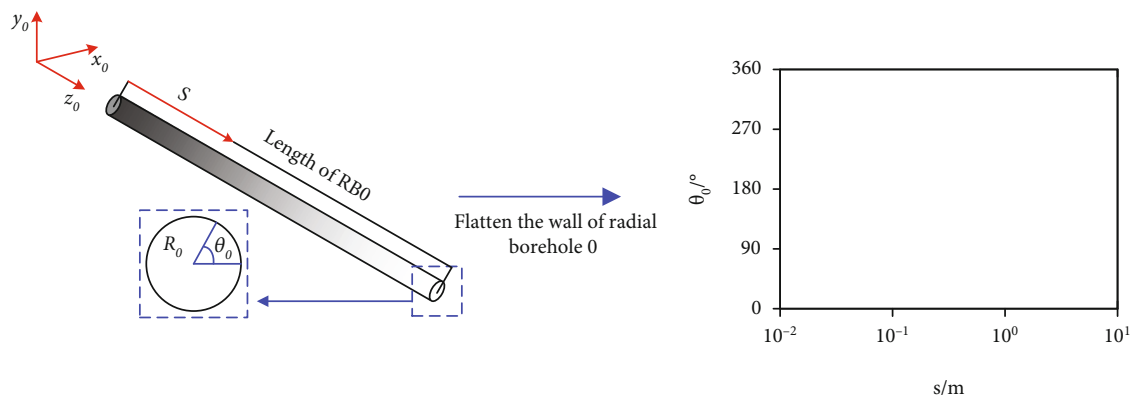

FIGURE 3: Schematic diagram of flattening the radial borehole 0 wall.

TABLE 1: Basic calculation parameters.

\begin{tabular}{lcc}
\hline Parameter & Value & Unit \\
\hline Maximum horizontal in situ stress, $\sigma_{H}$ & 48 & $\mathrm{MPa}$ \\
Minimum horizontal in situ stress, $\sigma_{h}$ & 40 & $\mathrm{MPa}$ \\
Vertical in situ stress, $\sigma_{v}$ & 50 & $\mathrm{MPa}$ \\
Poisson's ratio of rock, $v_{r}$ & 0.2 & - \\
Young's modulus of rock, $E_{r}$ & 50 & $\mathrm{GPa}$ \\
Young's modulus of the casing, $E_{c}$ & 135 & $\mathrm{GPa}$ \\
Exterior radius of the main wellbore, $R_{e}$ & 0.18 & $\mathrm{~m}$ \\
Interior radius of the main wellbore, $R_{i}$ & 0.165 & $\mathrm{~m}$ \\
Radius of radial borehole $0, R_{0}$ & 0.015 & $\mathrm{~m}$ \\
Radius of radial borehole $1, R_{1}$ & 0.015 & $\mathrm{~m}$ \\
Internal pressure, $P_{w}$ & 45 & $\mathrm{MPa}$ \\
Initial pore fluid pressure, $P_{p}$ & 20 & $\mathrm{MPa}$ \\
Permeability coefficient, $\delta$ & 0.9 & - \\
Formation porosity, $\phi$ & 0.15 & - \\
Biot coefficient, $\varepsilon$ & 0.55 & - \\
Azimuth angles of radial borehole $0, \beta_{0}$ & 45 & Degree \\
Intersection angle of radial boreholes, $\varphi$ & 0 & Degree \\
Depth difference between radial boreholes, $L$ & 0.05 & $\mathrm{~m}$ \\
Tensile strength of rock, $\sigma_{T}$ & 8 & $\mathrm{MPa}$ \\
\hline
\end{tabular}

0 , and a serial of sensitivity analysis of different parameters are conducted, such as intersection angle of radial boreholes, the radius of radial boreholes, depth difference between radial boreholes, Biot coefficient, and the number of radial boreholes. Meanwhile, as illustrated in Figure 3, the wall of radial borehole 0 is flattened into a plane, called radial borehole 0 plane, to visually display the situation of borehole wall.

The increment of maximum tensile stress on the wall of radial borehole 0 , which caused by the presence of radial borehole 1, can be considered as the interference between boreholes and forms the guidance of radial borehole 1 to the fracture from radial borehole 0 . Based on the difference in the maximum tensile stress distribution with single radial borehole 0 and the maximum tensile stress distribution with both radial boreholes, the increment of maximum tensile stress caused by radial borehole 1 can be calculated, and the maximum tensile stress increasing zone can be plotted on radial borehole 0 plane. Through the above methodology, the interference between radial boreholes is quantified and analyzed. The basic calculation parameters are shown in Table 1.

3.1. The Effect of Radial Borehole Intersection Angle. In this part, the other parameters are set to basic calculation parameters, and the intersection angle of radial boreholes, $\varphi$, is changed to analyze its effect on the interference between radial boreholes and fracture initiation pressure.

3.1.1. The Sensitivity of FIP. As shown in Figure 4, as the intersection angle of radial boreholes increasing from $0^{\circ}$ to $25^{\circ}$, FIP increases rapidly at first and then stays pretty constant when the intersection angle exceeds $10^{\circ}$. When the intersection angle between two radial boreholes is small, the additional maximum tensile stress increase caused by radial borehole 1 roughly overlaps with the maximum tensile stress concentration region of radial borehole 0 wall, the zone around $\theta_{0}=90^{\circ}$. Thus, lower FIP can be attained when the intersection angle is below $10^{\circ}$. The additional maximum tensile stress decreases, and the region with additional stress increase deviates from $\theta_{0}=90^{\circ}$ when intersection angle, $\varphi$, increases, which conduce the rapid growth of FIP. When the intersection angle of radial boreholes is more than $10^{\circ}$, it can be considered that the expansion of the angle does not affect FIP anymore.

3.1.2. The Sensitivity of Interference. As shown in Figures 5 and 6 , the inference caused by radial borehole 1 decreases with the growth of intersection angle, $\varphi$. When $\varphi=0^{\circ}$, the maximum tensile stress increasing region is distributed along the whole length of radial hole 0 , and the highest increase of maximum tensile stress caused by radial hole 1 is the largest. At this time, radial borehole 1 has an excellent guiding strength to the fracture from radial borehole 0 , encouraging fracture to extend toward radial boreholes 1 and connect two boreholes. With the further increase of $\varphi$ from $5^{\circ}$ to $20^{\circ}$, the maximum growth of maximum tensile stress gradually decreases, and the maximum tensile stress increasing region also shrinks and shifts. The distance between two boreholes starts to enlarge along radial borehole 0 when $\varphi$ $>0^{\circ}$, and the growth rate of distance positively correlates with intersection angle, $\varphi$. Therefore, the region near the root of borehole 0 , about $s<0.7 \mathrm{~m}$, still can be guided well at $\varphi$ $=5^{\circ}$, and nearly, no area can be directed at $\varphi=20^{\circ}$. The 


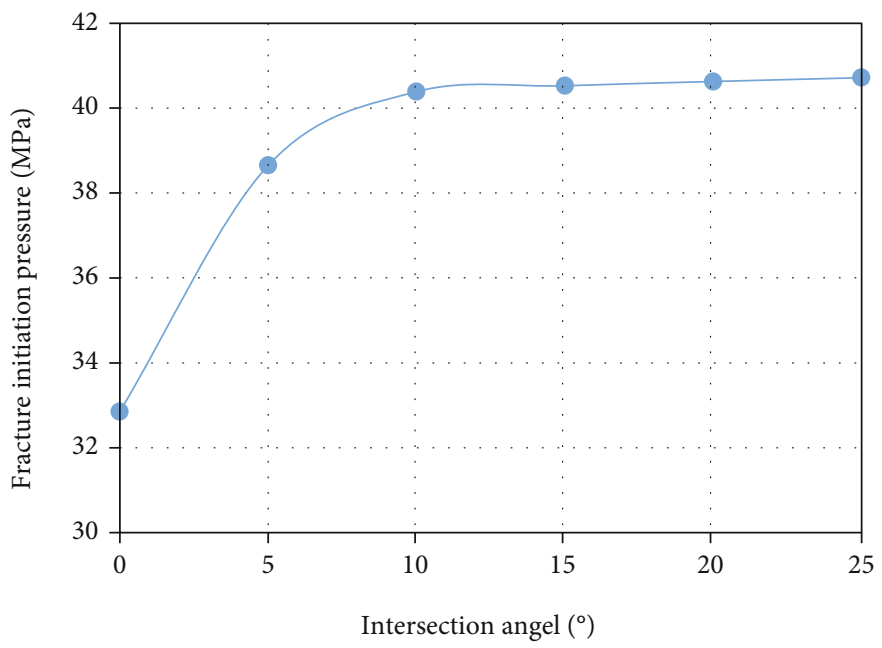

FIGURE 4: FIP with different intersection angles between radial boreholes.
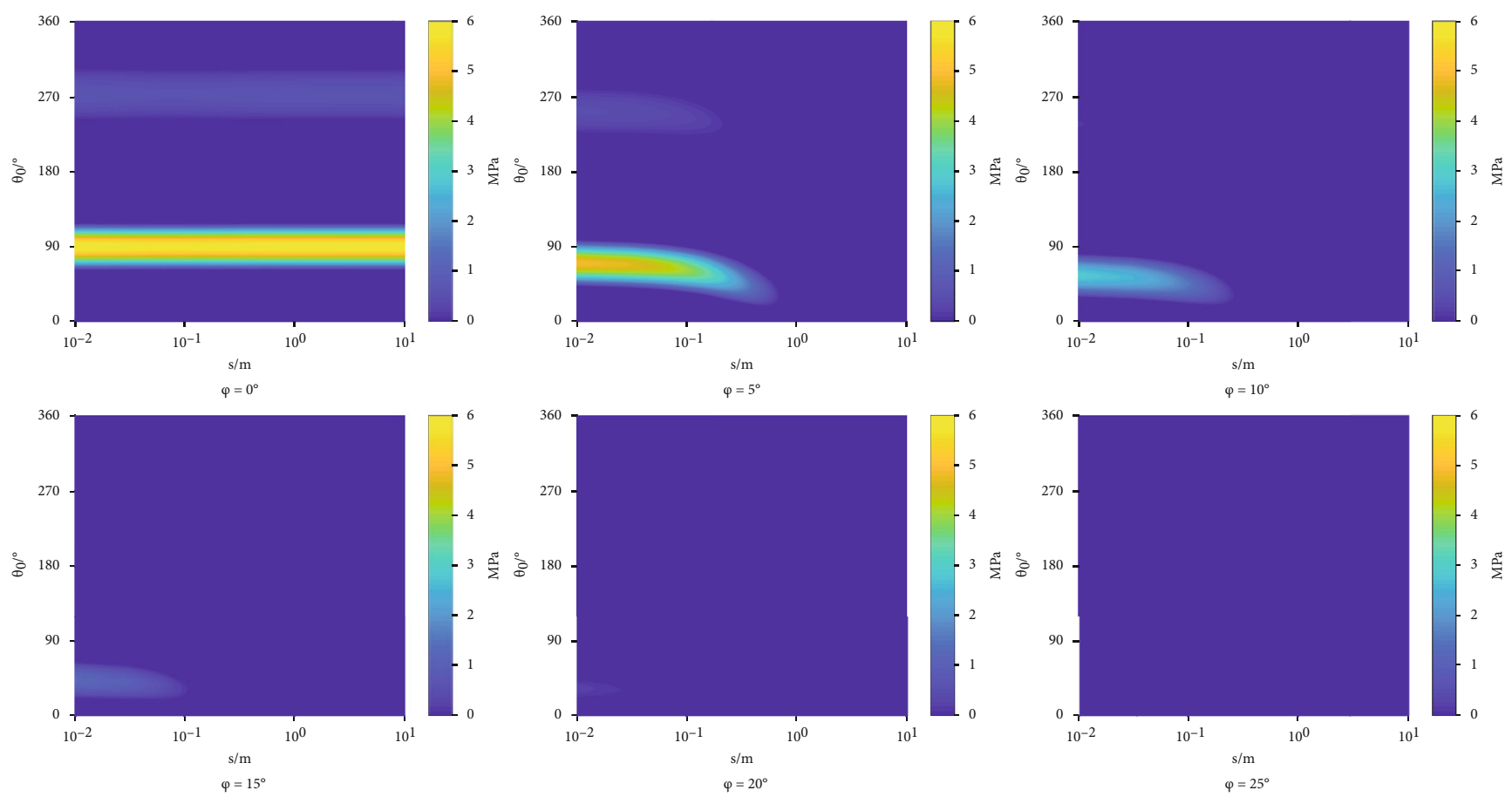

FIgURE 5: Maximum tensile stress increasing region with different intersection angles.

highest increase of maximum tensile stress falls to 0 at $\varphi=25^{\circ}$ , and it can be considered that radial borehole 1 no longer has interference to the fracture from radial borehole 0 .

3.2. The Effect of Radial Borehole Depth Difference. For radial borehole 1 virtually does no influence FIP of radial borehole 0 when $\varphi>10^{\circ}$, the depth difference is changed to analyze the effect of depth difference in the condition of that the intersection angle, $\varphi$, is fixed to $0^{\circ}$, and the other parameters take the value of basic calculation parameters.

3.2.1. The Sensitivity of FIP. As illustrated in Figure 7, with the increase of depth difference from $40 \mathrm{~mm}$ to $90 \mathrm{~mm}$, FIP increases rapidly firstly (depth difference $<60 \mathrm{~mm}$ ), then ascends slowly, because the increasing distance between boreholes weakens the action of additional stress field caused by radial borehole 1 and heightens FIP.

3.2.2. The Sensitivity of Interference. As illustrated in Figures 8 and 9, the area of stress increasing region and the increasing growth of maximum tensile stress reduce with the increase of depth difference from $40 \mathrm{~mm}$ to $90 \mathrm{~mm}$, representing the declining trend of interference and guidance of radial borehole 1 . When the depth difference is small ( $L<50 \mathrm{~mm}$ ), a higher increment of maximum tensile stress can be attained, and even both top and bottom sides $\left(\theta_{0}=90^{\circ}, 270^{\circ}\right)$ of radial borehole 0 can be affected by addition stress field. As depth difference continues to increase, 


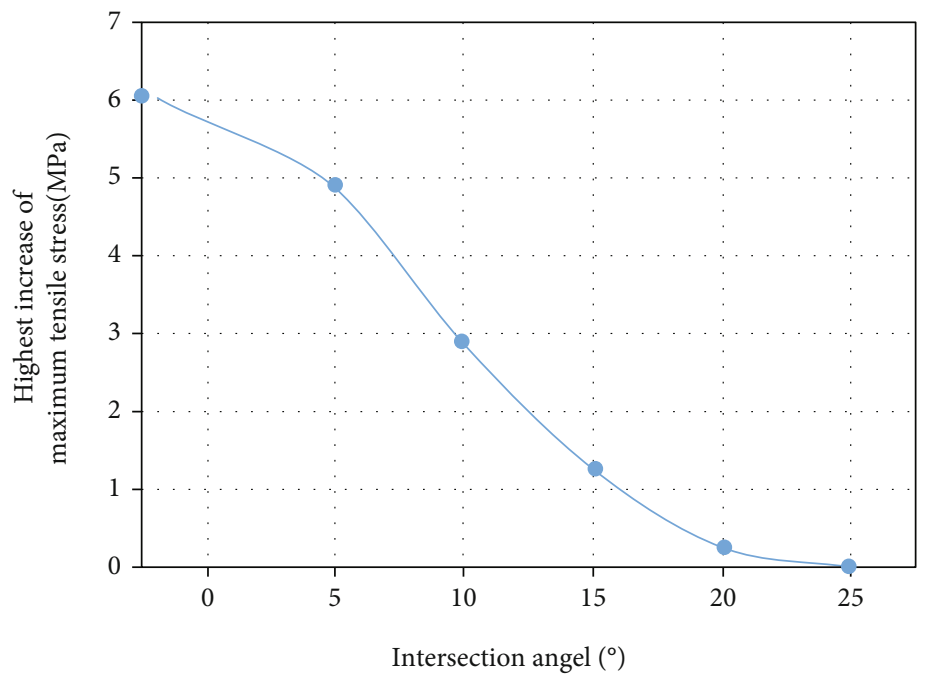

FIGURE 6: Highest increment of maximum tensile stress with different intersection angles.

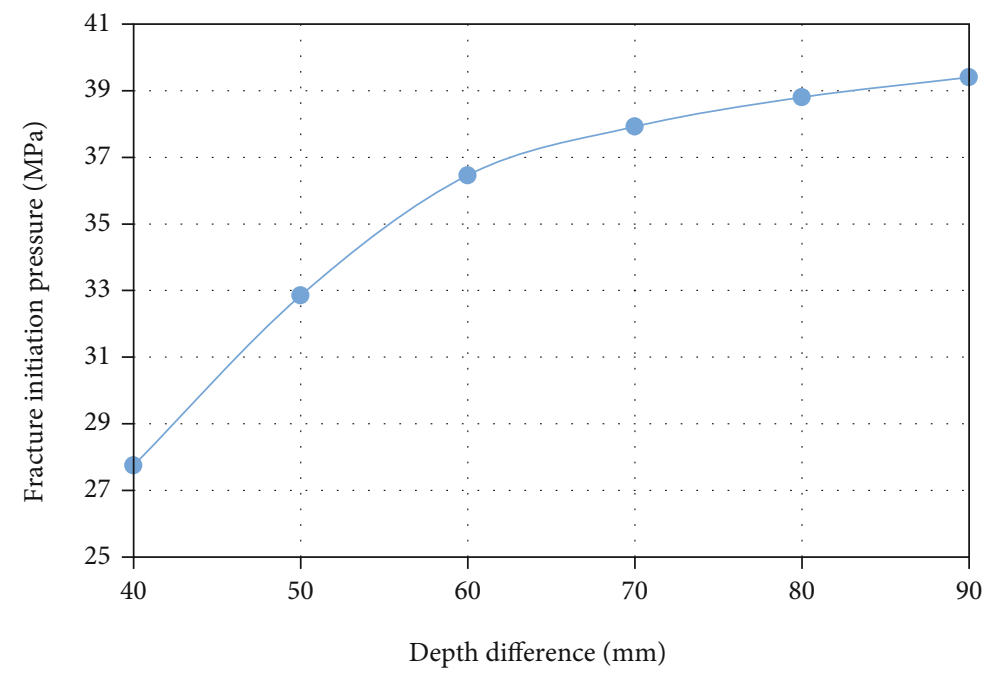

Figure 7: FIP with different depth differences of radial boreholes.

the stress growth region moderately decreases, and the rising degree of maximum tensile stress gradually decreases. The highest increase of maximum tensile stress on the wall of radial borehole 0 has been reduced to $0.1076 \mathrm{MPa}$ when the depth difference reaches $90 \mathrm{~mm}$. It can be considered that radial borehole 0 is beyond the influencing domain of additional stress field caused by radial borehole 1 , and radial borehole 1 has no guidance to the fracture from radial borehole 0 when depth difference exceeds $90 \mathrm{~mm}$.

3.3. The Effect of Radial Borehole Radius. According to the previous study (Liu et al., 2018), the radius of the radial borehole has virtually no influence on its own FIP in the hydraulic fracture guided by single radial boreholes. However, the situation will be different in the case of multiradial boreholes. Due to the interference between radial boreholes, the radius of a particular radial borehole may affect FIP of the other radial boreholes. Thereby, depth difference is fixed as $90 \mathrm{~mm}$; the other parameters are set to basic calculation parameters, and the radius of radial borehole 1 is changed to analyze its effect on radial borehole 0 .

3.3.1. The Sensitivity of FIP. As illustrated in Figure 10, fracture initiation pressure decreases at a nearly uniform speed as the radius of radial borehole $1, R_{1}$, increasing. The increase of radial borehole 1 radius enhances the interference between boreholes and benefits the fracture initiation from the radial borehole 0 .

3.3.2. The Sensitivity of Interference. As illustrated in Figures 11 and 12, both of the maximum tensile stress increasing region and the growth of maximum tensile stress augment in the pace of radius of radial borehole 1 increasing. The case of $R_{1}=25 \mathrm{~mm}$ can be considered as a critical value for that only one side of borehole 0 , top side, is affected by radial borehole 1 when $R_{1}<25 \mathrm{~mm}$, and both sides of radial borehole 0 will be affected by radial borehole 1 if $R_{1} \geq 25 \mathrm{~mm}$. To get further study about the influence of radial borehole 

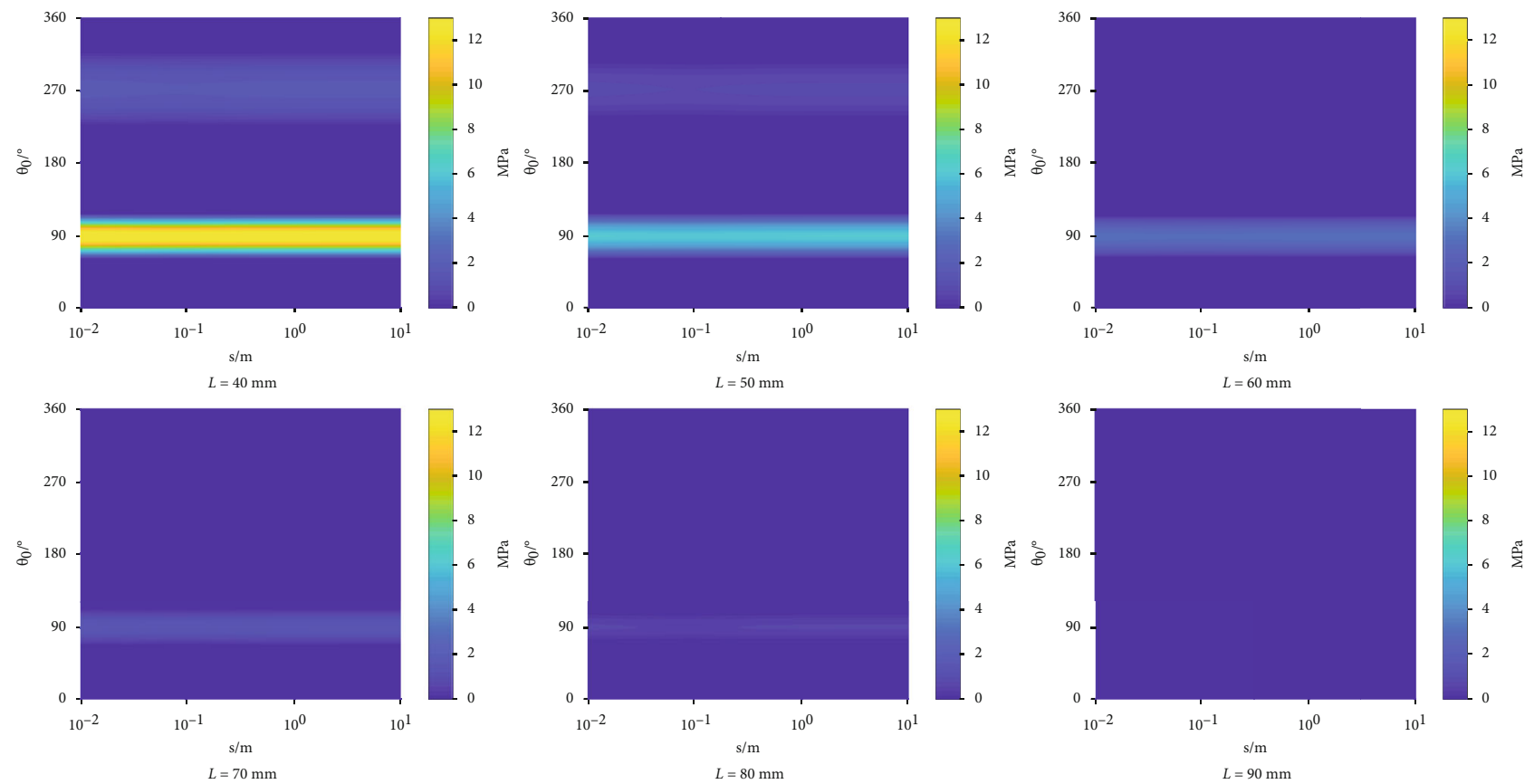

FIGURE 8: Maximum tensile stress increasing region with different depth differences.

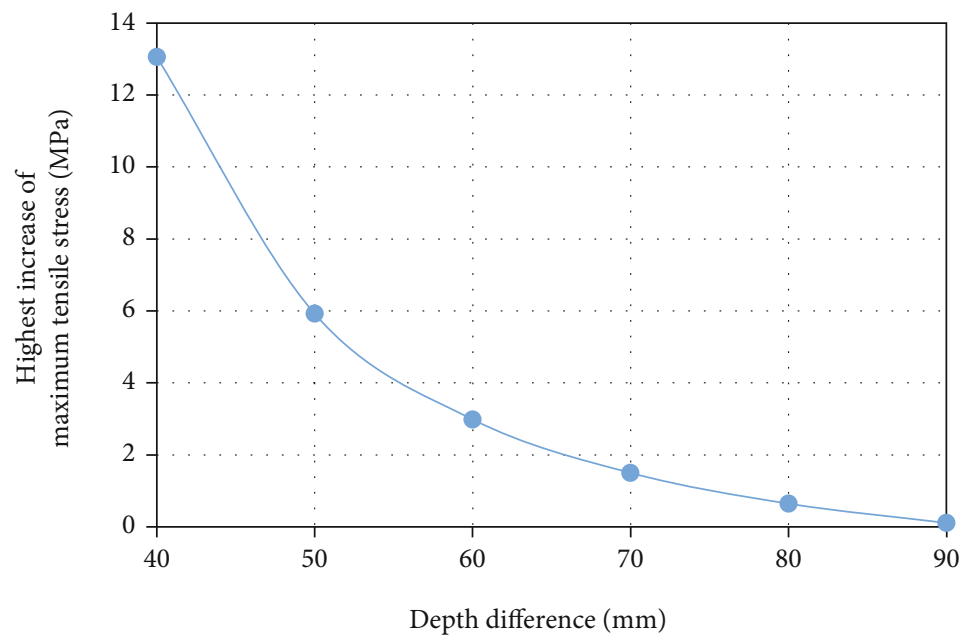

FIGURE 9: Highest increment of maximum tensile stress with different depth differences.

radius on the magnitude of the region where radial borehole can generate guidance, two groups of calculations are carried out, respectively. In one group, fix the depth difference, $L$, to $50 \mathrm{~mm}$ and calculate the intersection angle when the maximum tensile stress increment decreases to 0 under different radius and define the angle at this time as the critical intersection angle, $\varphi_{c}$. In the other group, fix the intersection angle, $\varphi$, to $0^{\circ}$ and calculate the depth difference when the maximum tensile stress increment decreases to 0 under different radius and define the depth difference at this time as the critical depth difference, $L_{c}$.

From Figures 13 and 14, both of the critical depth difference and critical intersection angle increase as the radius of radial borehole 1 increasing. The critical depth difference represents the longitudinal size of the region where radial borehole can generate interference and guidance. As the radius increases, the critical depth difference increases at a uniform speed. Every time the radius increases by $1 \mathrm{~mm}$, the critical depth difference increases by $5.2 \mathrm{~mm}$. Meanwhile, the critical intersection angle represents the transverse size of the region where radial borehole can generate interference and guidance. The critical angle increases with the increase of radius, but the increasing speed is decreasing gradually.

3.4. The Effect of Biot Coefficient. Biot coefficient is one of the basic parameters of formation rock and plays an essential role in hydraulic fracture design. In this part, Biot coefficient is changed, and the other parameters adopt the value of basic calculation parameters to study the effect of Biot coefficient. 


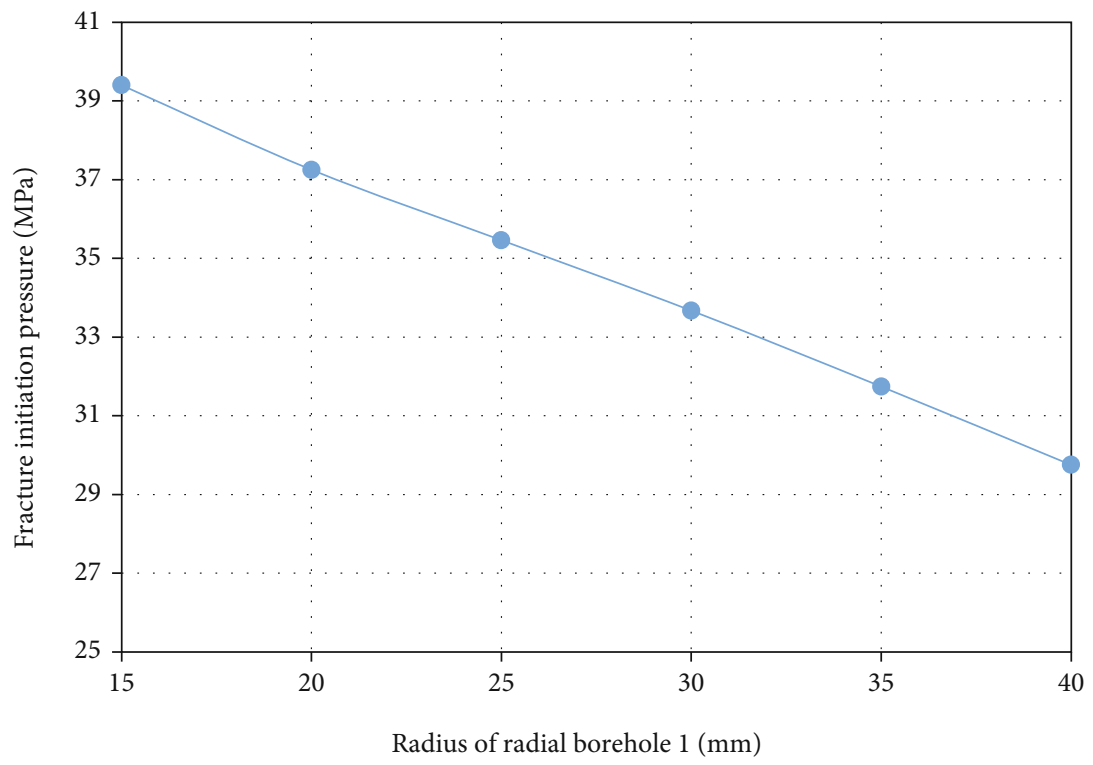

FIgURE 10: FIP with different radius of radial borehole 1.
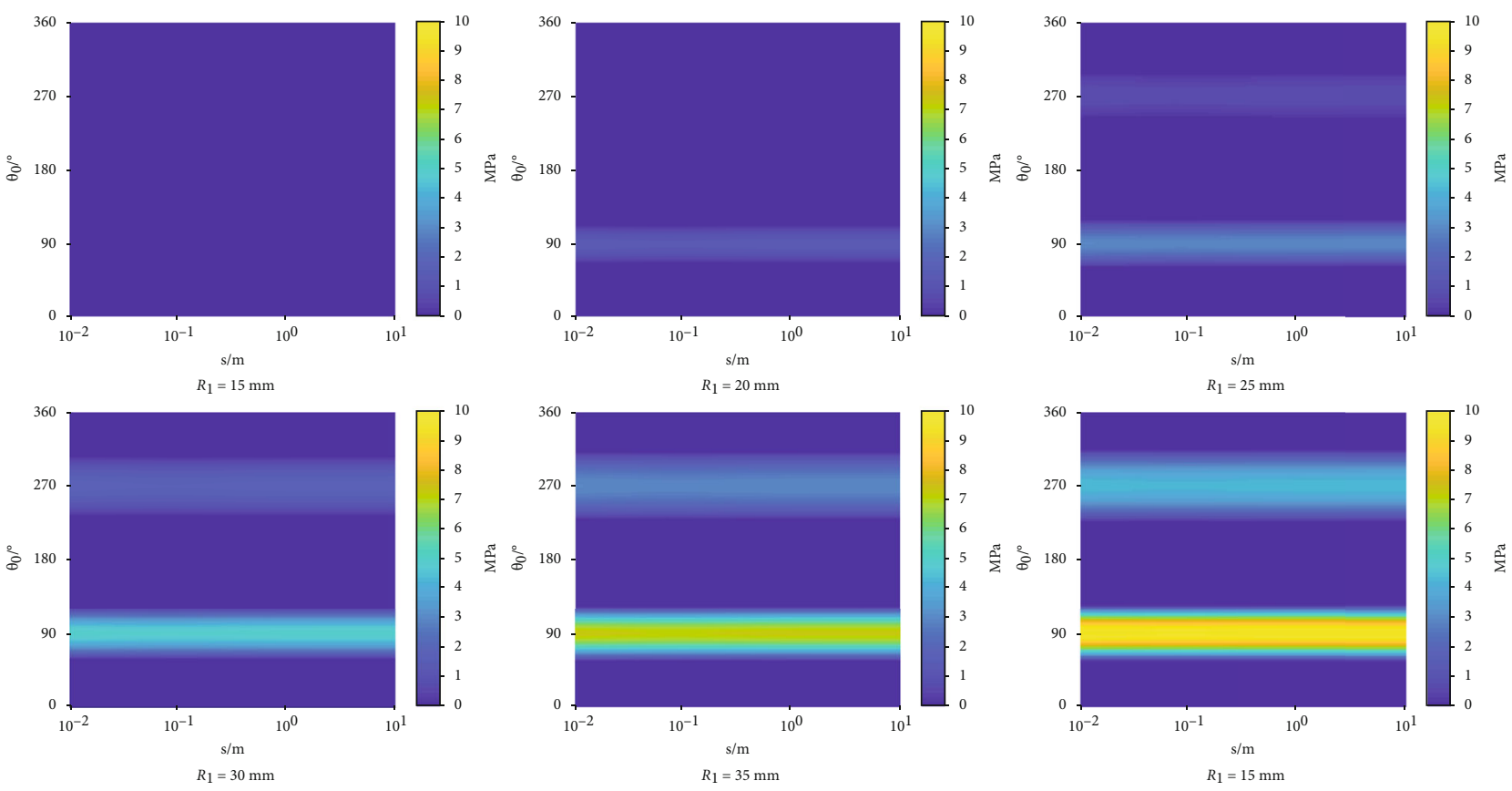

FIgURE 11: Maximum tensile stress increasing region with different radius of radial borehole 1.

3.4.1. The Sensitivity of FIP. As illustrated in Figure 15, fracture initiation pressure increases as the Biot coefficient rising. Besides, the growth rate of FIP accelerates slightly with the increase of Biot coefficient. Thus, a low Biot coefficient is helpful to fracture initiation and obtain a low fracture initiation pressure.

3.4.2. The Sensitivity of Interference. It can be seen from Figures 16 and 17 that with the increase of Biot coefficient, the maximum tensile stress increasing region and the highest growth of maximum tensile stress are both shrinking. Besides, there is an excellent linear relationship between the highest increment of maximum tensile stress and Biot coefficient. When the Biot coefficient increases by 0.1, the highest increment of maximum tensile stress decreases by $0.89 \mathrm{MPa}$. Similar to the analysis of radius of radial borehole 1 , the critical depth difference, $L_{c}$, and critical intersection angle, $\theta_{c}$, are calculated separately with the fixed intersection angle of $0^{\circ}$ and the fixed depth difference of $50 \mathrm{~mm}$, respectively, to study the influence of Biot coefficient on the interference range of radial borehole 1 .

As shown in Figures 18 and 19, with the increase of Biot coefficient, the critical intersection angle and critical depth difference have a similar decreasing trend, which means that the interference region of radial borehole 1 decreases with the increase of Biot coefficient. This means that the low Biot 


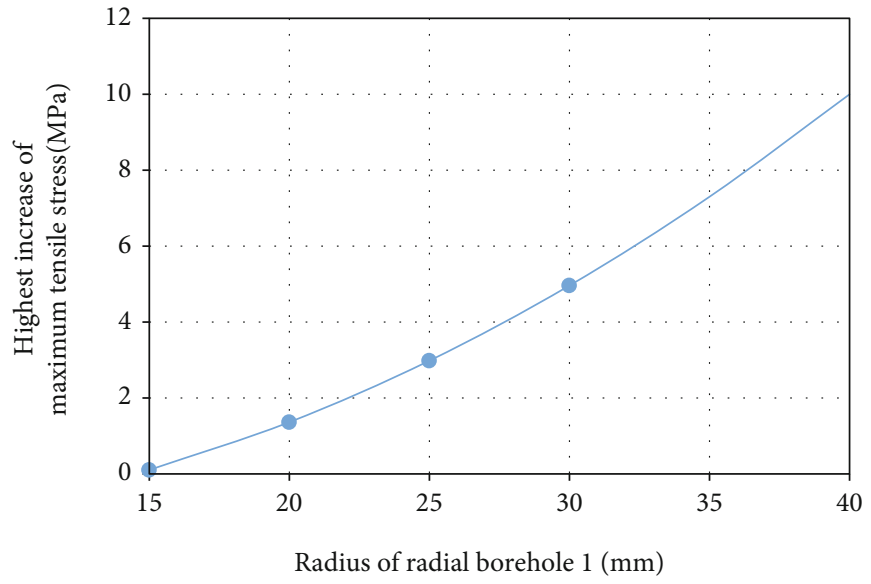

FIGURE 12: Highest increment of maximum tensile stress with different radius of radial borehole 1.

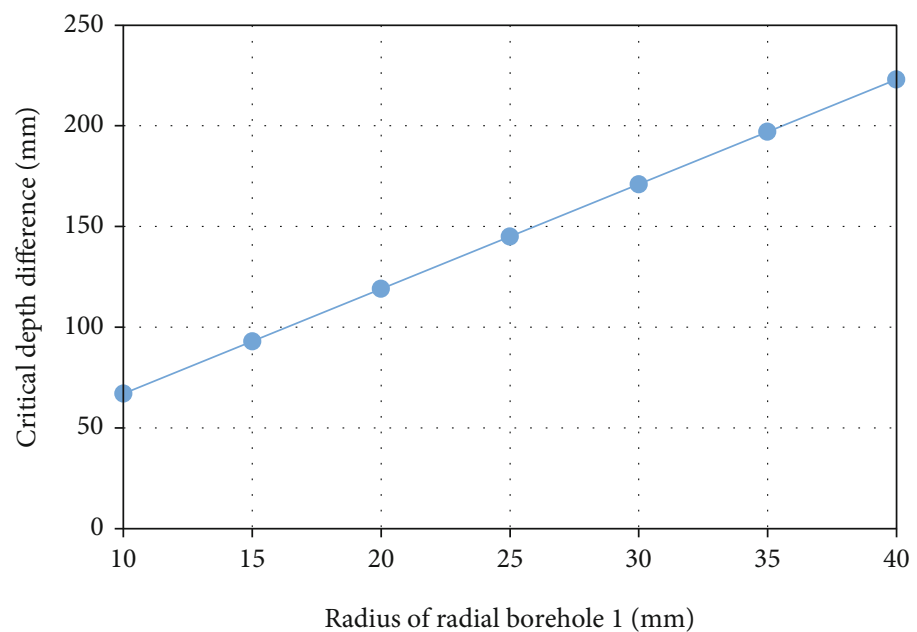

FIGURE 13: Critical depth difference with different radius of radial borehole 1.

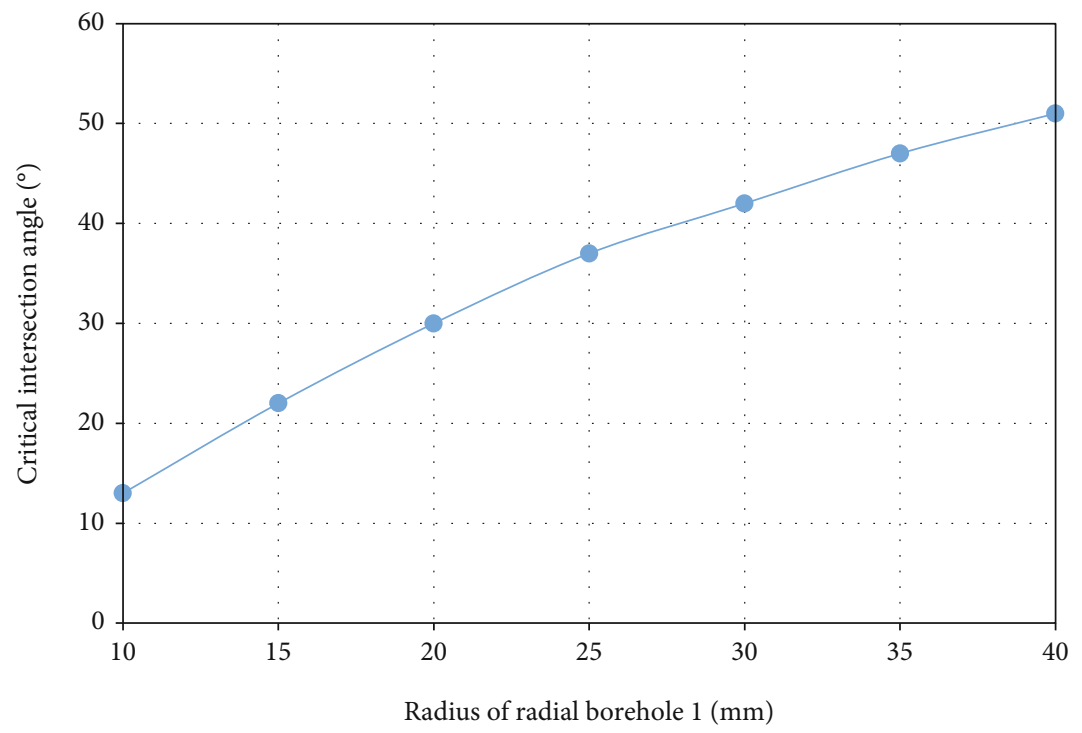

FIGURE 14: Critical intersection angle with different radius of radial borehole 1 . 


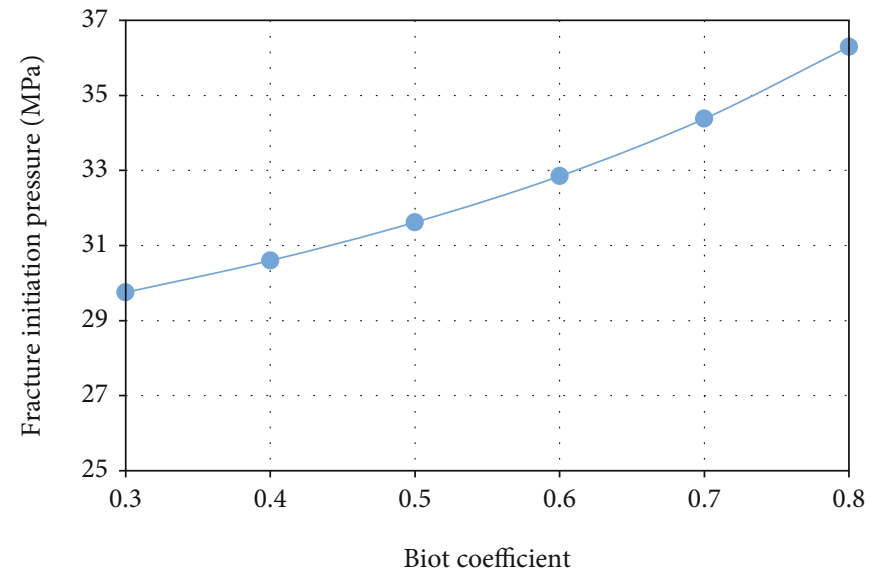

FIGURE 15: FIP with different Biot coefficient.
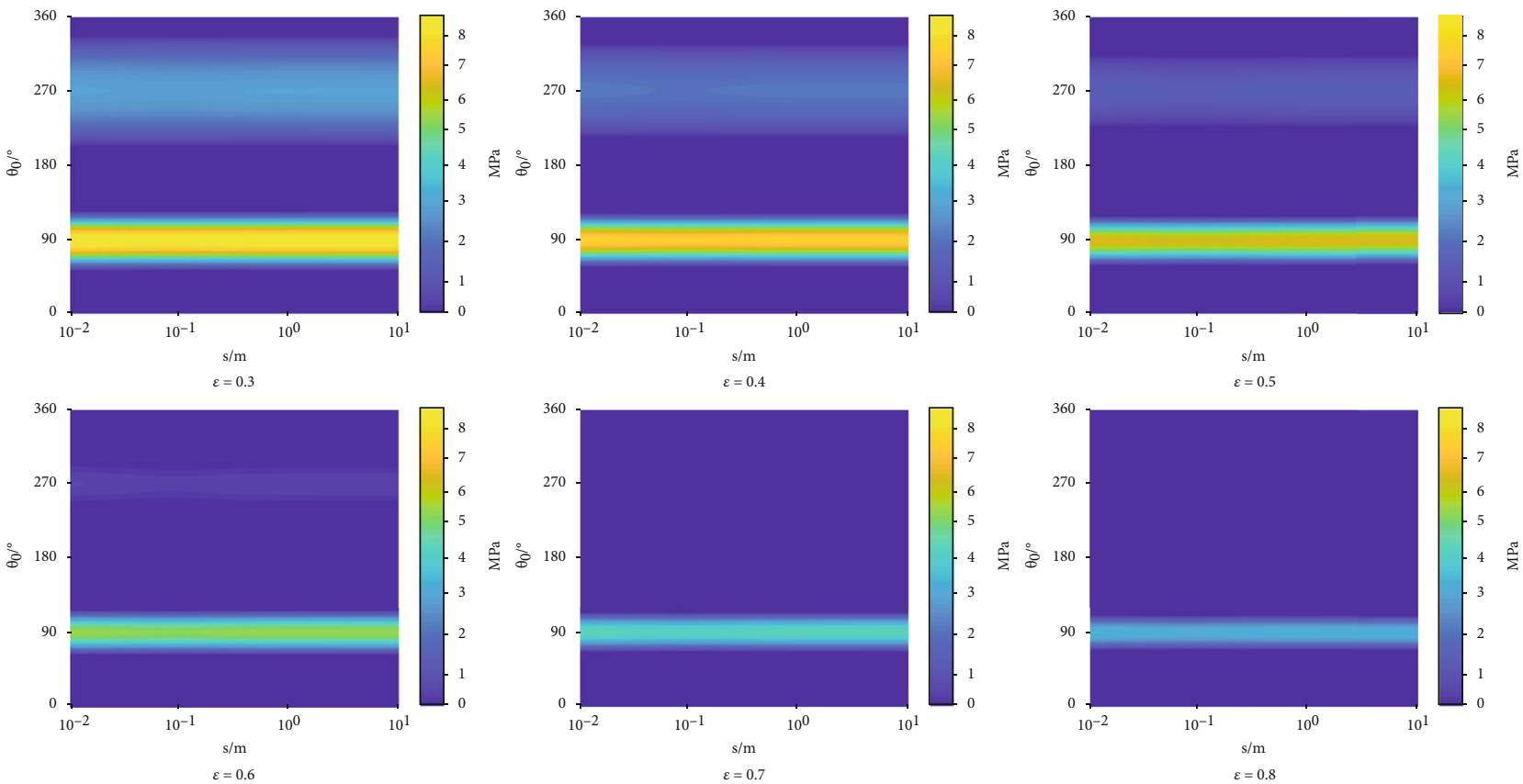

FIGURE 16: Maximum tensile stress increasing region with different Biot coefficient.

coefficient is conducive to expand the influence range of additional stress field caused by radial borehole 1, which guides fracture to connect radial boreholes and conduces the form of the fracture network. Also, the declining pace of both critical intersection angle and critical depth difference decreases with the increment of Biot coefficient.

3.5. The Effect of Radial Borehole Number. In this part, the multi-radial borehole model is compared with the single radial borehole model proposed by Liu [20] to analyze the influence of additional radial boreholes. Meanwhile, the existing model can be extended easily to conditions with arbitrary number of radial boreholes through simple steps. The specific steps are not described in this article. In this part, the other parameters are set to basic calculation parameters, and the number of radial boreholes is changed. All radial boreholes have the same azimuth angles, and the depth difference between adjacent radial boreholes is fixed to $50 \mathrm{~mm}$. The radial borehole in the middle is taken as the research object. According to the change of FIP and highest increment of maximum tensile stress, the influence of radial boreholes number is studied.

3.5.1. The Sensitivity of FIP. It can be seen from Figure 20, with the increase of the number of radial boreholes, FIP decreases promptly first, then slows down gradually and finally decreases by $23.7 \%$ to $31.3 \mathrm{MPa}$. The maximum decrease of FIP occurs when the number of radial boreholes changes from 1 to 2 . Compared with single radial borehole, FIP of double radial boreholes decreases by $20.2 \%$ due to one additional radial borehole. Therefore, in the formation where fracture is hard to initiate, multi-radial boreholes, 


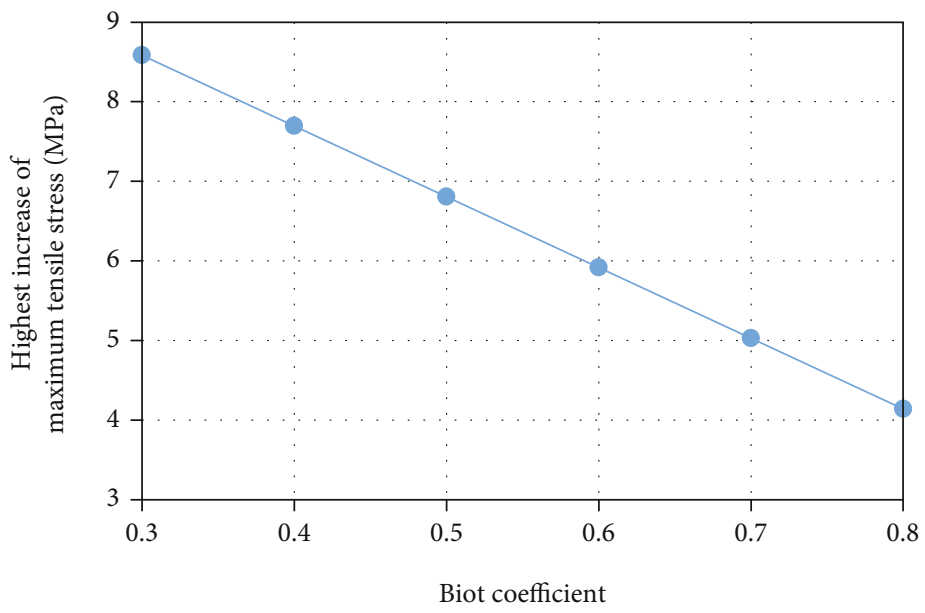

FIGURE 17: Highest increment of maximum tensile stress with different Biot coefficient.

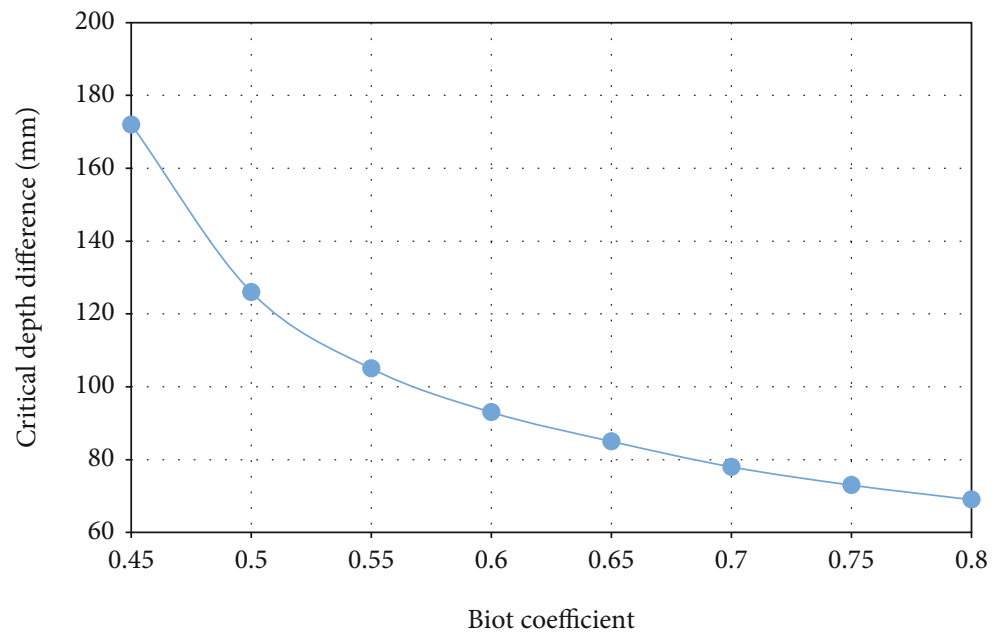

FIGURE 18: Critical depth difference with different Biot coefficient.

compared with single borehole, can effectively reduce FIP and induce fracture initiation. However, when number of radial boreholes adds up to 3, continually increasing the number of radial boreholes has little effect on the FIP. At this time, it is no longer a feasible choice to reduce FIP by increasing the number of radial boreholes.

3.5.2. The Sensitivity of Interference. As shown in Figures 21 and 22, highest increment of maximum tensile stress grows up with the increase of radial borehole number. Comparing double radial boreholes with single radial borehole, the additional radial borehole increases the maximum tensile stress on borehole wall by $6.12 \mathrm{MPa}$. Meanwhile, due to the same orientation of the radial boreholes, maximum tensile stress increasing region appears near the top and bottom of radial borehole $\left(\theta=90^{\circ}\right.$ and $\left.180^{\circ}\right)$. However, the increase rate slows down rapidly with the increase of radial borehole number. When the number of radial boreholes exceeds 3, the influence of radial borehole number on highest increment of maximum tensile stress nearly can be neglected.

\section{Conclusion and Recommendation}

In this paper, an analytical model for fracture initiation in hydraulic fracturing guided by multi-radial boreholes is established. The model can be used to calculate the fracture initiation pressure of one particular radial borehole and the additional stress field on its wall caused by the other radial boreholes. Then, a series of sensitivity analysis is performed by examining the effects of different parameters, including the intersection angle between radial boreholes, the depth difference, radius of the radial borehole, Biot coefficient, and the number of radial boreholes. The major conclusions are:

(1) In the hydraulic fracturing guided by multi-radial boreholes, FIP declines with the decrease of intersection angle only when the intersection angle between radial boreholes is small $\left(\varphi<25^{\circ}\right)$. When the intersection angle is $0^{\circ}$, the fracture initiation pressure decreases to the minimum. Therefore, if it is necessary to obtain low fracture initiation pressure, all radial boreholes should protrude in the same 


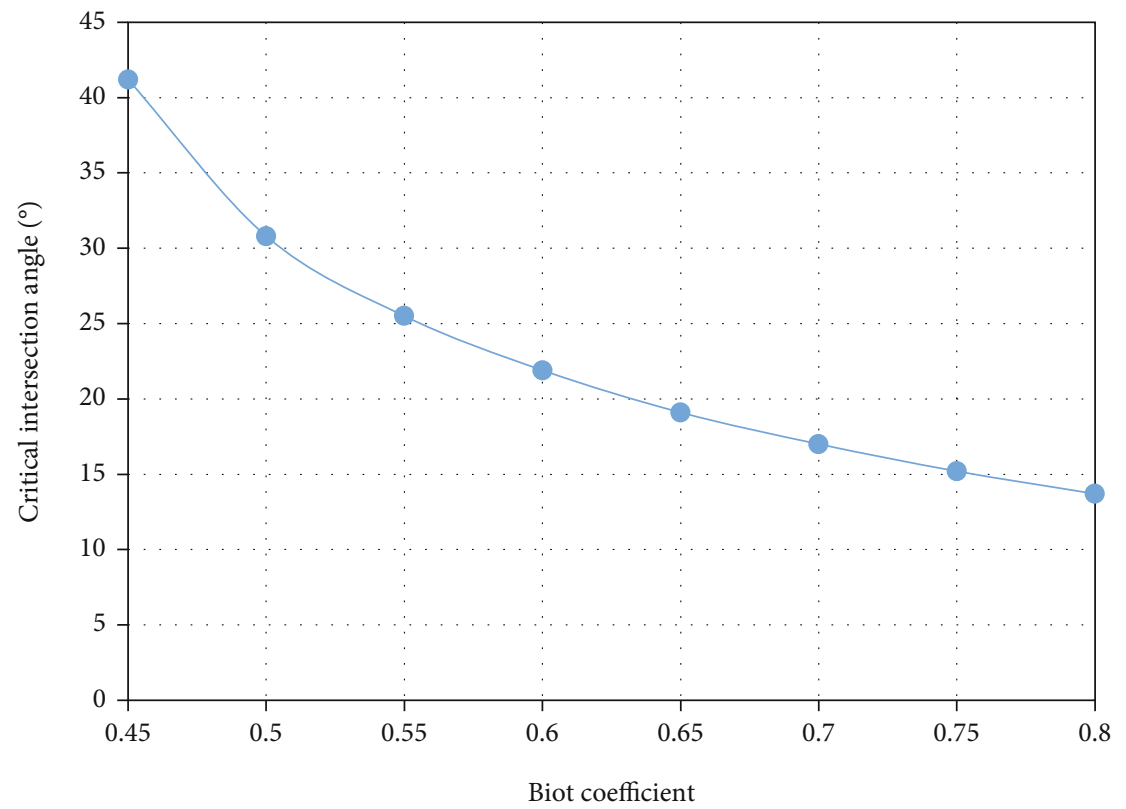

FIgURE 19: Critical intersection angle with different Biot coefficient.

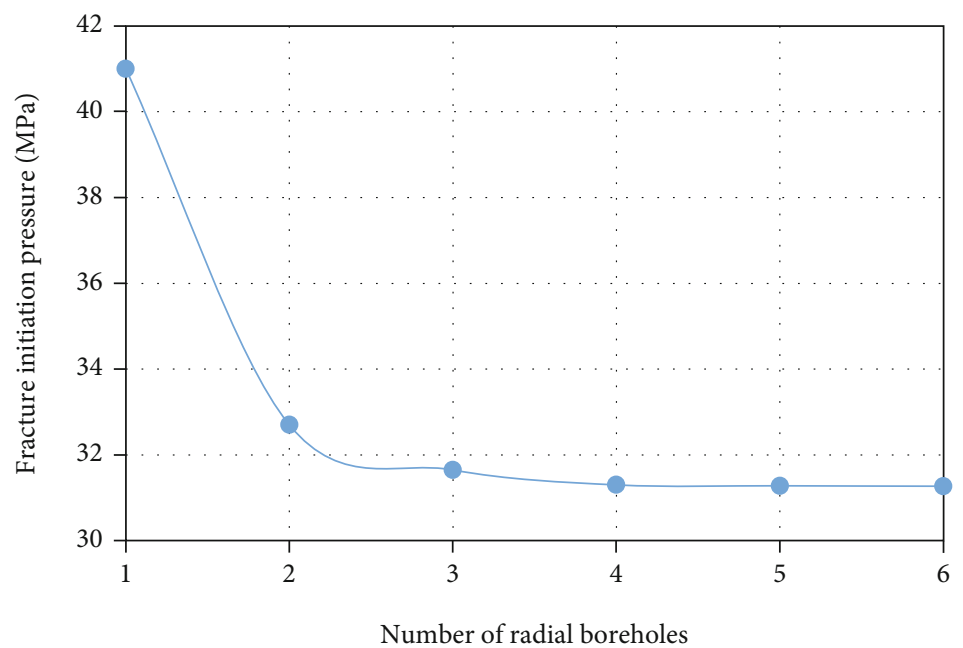

FIGURE 20: FIP with different number of radial boreholes.

direction as far as possible. Besides, the increase of intersection angle will weaken the mutual interference between boreholes in the range and degree, resulting in only the area near the main wellbore being guided, which is useless to the formation of fracture network between radial boreholes

(2) In the hydraulic fracturing guided by multi-radial boreholes, with the increase of radial depth difference between boreholes, FIP increases rapidly at first and then slowly. Therefore, to obtain low fracture initiation pressure, the depth difference between radial boreholes can be reduced to a certain extent within the allowable range of field conditions and casing strength. At the same time, the increase of the depth difference between radial boreholes will weaken the mutual interference between boreholes, which is not conducive to the formation of the fracture network between radial boreholes

(3) Although the radius of the radial borehole does not affect FIP when single radial borehole exists alone, the increase of radius will reduce FIP in the presence of multiradial boreholes. Therefore, the radius of radial boreholes can be appropriately increased in the formation with high fracture initiation pressure. At the same time, the increase of the radius of radial borehole can significantly expand the interference range of radial borehole, enhance the ability to guide fracture, and is conducive to the formation of fracture network between radial boreholes 

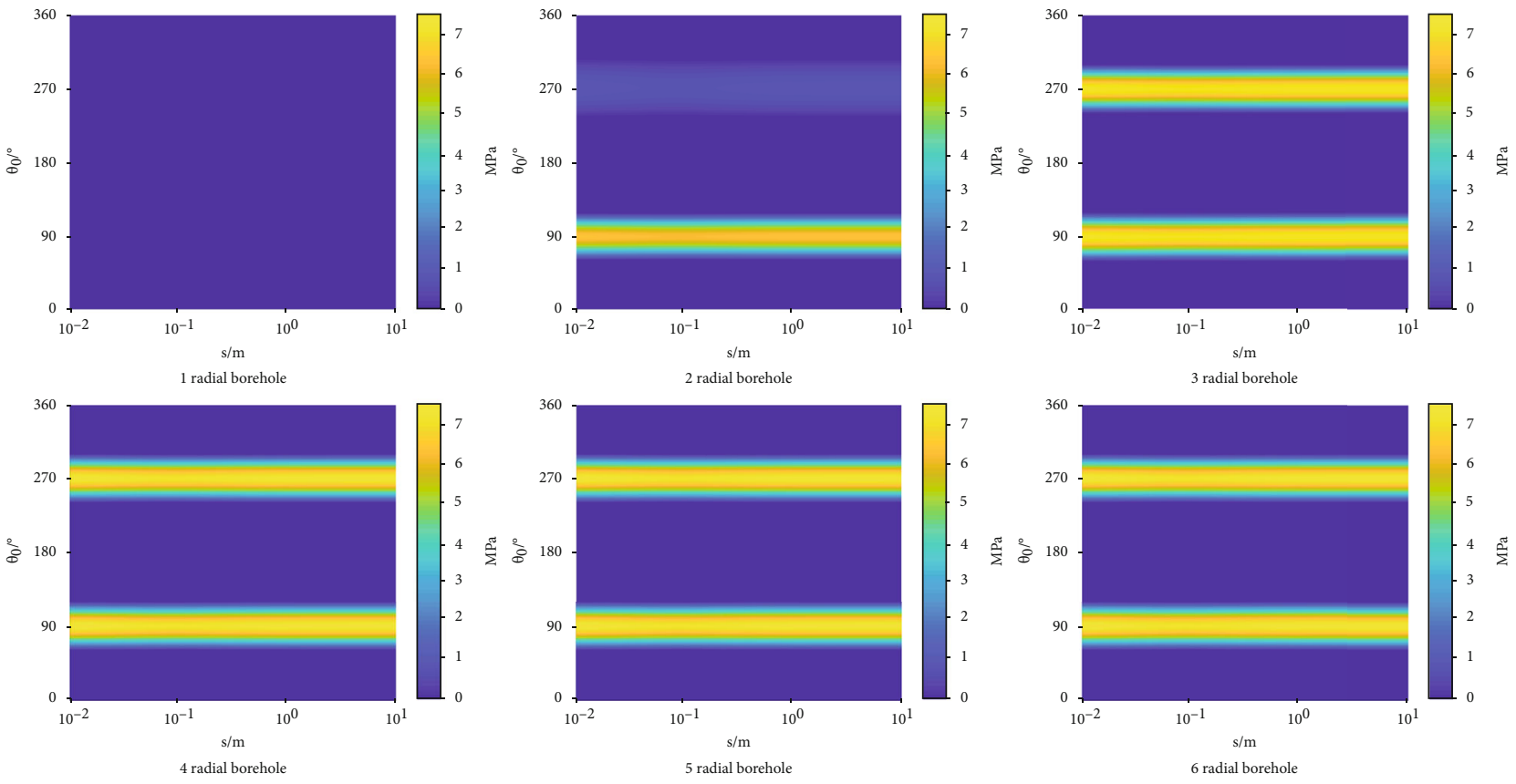

FIGURE 21: Maximum tensile stress increasing region with different radial borehole number.

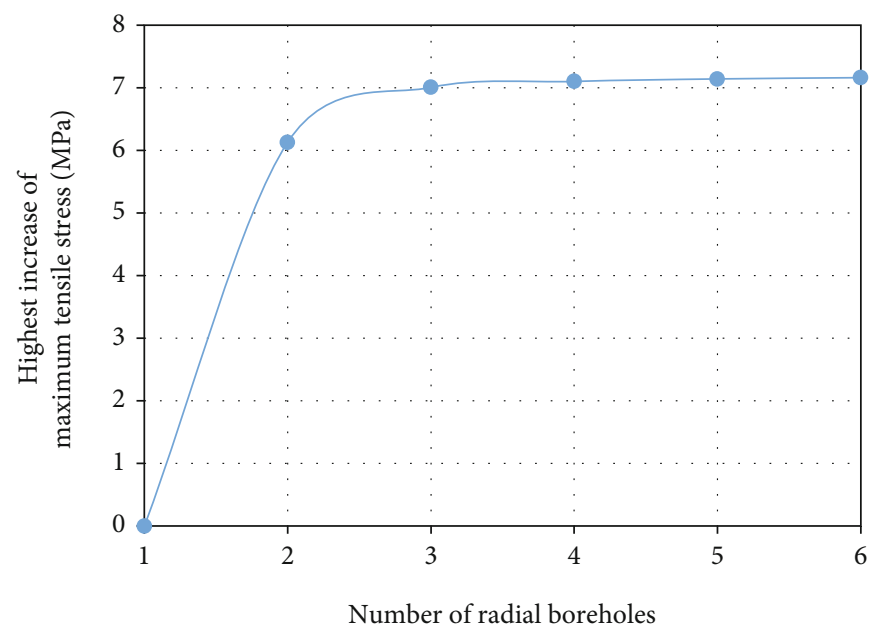

FiguRE 22: Highest increment of maximum tensile stress with different radial borehole number.

(4) In the hydraulic fracturing guided by multi-radial boreholes, low Biot coefficient is beneficial to fracture initiation and obtain low FIP. At the same time, low Biot coefficient can enhance the interference between radial boreholes, expand the influence range of additional stress field, and conduce the fracture network connecting radial boreholes

(5) Compared with single radial borehole, multi-radial boreholes can reduce FIP significantly. Due to one additional radial borehole, FIP of double radial boreholes is reduced by $20.2 \%$. If the number of radial boreholes continues to increase, FIP can be reduced by $23.7 \%$ at most. Thus, in the formation with a high FIP, increasing the number of radial boreholes is a good choice to obtain a lower FIP, which can reduce the requirements of operation equipment and enhance the operation safety. However, the declining rate of FIP decreases as the number of radial boreholes increasing. When the number of radial boreholes exceeds 3, FIP basically remains steady. At this time, it will no longer be a good option to reduce FIP by continually increasing the number of boreholes for the low reduction of FIP and the expense of additional radial drilling

(6) In the design of hydraulic fracturing guided by multiradial boreholes, the analytical model can be used to calculate the FIP of each radial borehole and analyze the interference between radial boreholes to optimize 
the layout and parameters of radial boreholes, to obtain lower fracture initiation pressure and better formation of the fracture network between radial boreholes

\section{Data Availability}

All data included in this study are available upon request by contact with the corresponding author.

\section{Conflicts of Interest}

The authors declare that they have no known competing financial interests or personal relationships that could have appeared to influence the work reported in this paper.

\section{Acknowledgments}

This study was financially supported by the National Science and Technology Major Projects of China (Grant No. 2017ZX05030-05).

\section{References}

[1] W. Dickinson and R. Dickinson, "Horizontal radial drilling system," in SPE California Regional Meeting Society of Petroleum Engineers, Bakersfield, California, 1985.

[2] W. Dickinson, H. Dykstra, R. Nordlund, and W. Dickinson, "Coiled-tubing radials placed by water-jet drilling: field results, theory, and practice," in SPE Annual Technical Conference and Exhibition, Society of Petroleum Engineers, Houston, Texas, 1993.

[3] R. S. Balch, T. Ruan, M. Savage, and J. Harvard, "Field testing and validation of a mechanical alternative to radial jet drilling for improving recovery in mature oil wells," in SPE Western Regional Meeting, Society of Petroleum Engineers, Anchorage, Alaska, 2016.

[4] Y. Li, C. Wang, L. Shi, and W. Guo, "Application and development of drilling and completion of the ultrashort-radius radial well by high pressure jet flow techniques," in International Oil and Gas Conference and Exhibition in China, Beijing, 2000.

[5] S. Ursegov, A. Bazylev, and E. Taraskin, "First results of cyclic stimulations of vertical wells with radial horizontal bores in heavy oil carbonates (Russian)," in SPE Russian Oil and Gas Technical Conference and Exhibition, Moscow, 2008.

[6] W. Bin, L. Gensheng, H. Zhongwei, L. Jingbin, Z. Dongbo, and L. Hao, "Hydraulics calculations and field application of radial jet drilling," SPE Drilling \& Completion, vol. 31, no. 1, pp. 71$81,2016$.

[7] X. H. Tan, J. Y. Liu, X. P. Li, L. H. Zhang, and J. C. Cai, “A simulation method for permeability of porous media based on multiple fractal model," International Journal of Engineering Science, vol. 95, pp. 76-84, 2015.

[8] M. P. Megorden, H. Jiang, and P. J. D. Bentley, "Improving hydraulic fracture geometry by directional drilling in a coal seam gas formation," in SPE Unconventional Resources Conference and Exhibition-Asia Pacific, Brisbane, 2013.

[9] A. M. S. Ragab, "Improving well productivity in an Egyptian oil field using radial drilling technique," Journal of Petroleum and Gas Engineering, vol. 4, no. 5, pp. 103-117, 2013.
[10] S. D. Cinelli and A. H. Kamel, "Novel technique to drill horizontal laterals revitalizes aging field," in SPE/IADC Drilling Conference, Amsterdam, Netherlands, 2013.

[11] T. Guo, B. Liu, Z. Qu, D. Gong, and L. Xin, "Study on initiation mechanisms of hydraulic fracture guided by vertical multiradial boreholes," Rock Mechanics and Rock Engineering, vol. 50, no. 7, pp. 1767-1785, 2017.

[12] Y. Lu, S. Xiao, Z. Ge, Z. Zhou, and K. Deng, "Rock-breaking properties of multi-nozzle bits for tree-type drilling in underground coal mines," Energies, vol. 9, no. 4, p. 249, 2016.

[13] S. Zuo, Z. Ge, K. Deng, J. Zheng, and H. Wang, "Fracture initiation pressure and failure modes of tree-type hydraulic fracturing in gas-bearing coal seams," Journal of Natural Gas science and Engineering, vol. 77, article 103260, 2020.

[14] R. G. V. D. Ketterij and C. J. D. Pater, "Experimental study on the impact of perforations on hydraulic fracture tortuosity," in SPE European Formation Damage Conference, The Hague, Netherlands, 1997.

[15] M. M. Hossain, M. K. Rahman, and S. S. Rahman, "Hydraulic fracture initiation and propagation: roles of wellbore trajectory, perforation and stress regimes," Journal of Petroleum Science and Engineering, vol. 27, no. 3-4, pp. 129-149, 2000.

[16] T. P. Lhomme, C. J. Pater, and P. H. Helfferich, "Experimental study of hydraulic fracture initiation in Colton sandstone," in SPE/ISRM Rock Mechanics Conference, Irving, Texas, 2002.

[17] S. H. Fallahzadeh, S. R. Shadizadeh, and P. Pourafshary, "Dealing with the challenges of hydraulic fracture initiation in deviated-cased perforated boreholes," in Trinidad and Tobago Energy Resources Conference, Trinidad, 2010.

[18] O. P. Alekseenko, D. I. Potapenko, S. G. Cherny, D. Esipov, D. Kuranakov, and V. Lapin, "3-D modeling of fracture initiation from perforated non-cemented wellbore," in SPE Hydraulic Fracturing Technology Conference, The Woodlands, Texas, USA, 2012.

[19] D. G. Gong, Z. Q. Qu, T. K. Guo, Y. Tian, and K. H. Tian, "Variation rules of fracture initiation pressure and fracture starting point of hydraulic fracture in radial well," Journal of Petroleum Science and Engineering, vol. 140, pp. 41-56, 2016.

[20] L. Qingling, T. Shouceng, L. Gensheng et al., "An analytical model for fracture initiation from radial lateral borehole," Journal of Petroleum Science and Engineering, vol. 164, pp. 206-218, 2018.

[21] S. Timoshenko, S. Timoshenko, and J. Goodier, Theory of Elasticity, McGraw-Hill book Company, 1951.

[22] A. Lubinski, "The theory of elasticity for porous bodies displaying a strong pore structure," in Proceedings of the 2nd US National Congress of Applied Mechanics, pp. 247-256, Ann Arbor, Michigan, 1954. 